\title{
Photochemical upconversion: Present status and prospects for its application to solar energy conversion
}

\author{
Tim F. Schulze ${ }^{a}$ and Timothy W. Schmidt ${ }^{*}, b$
}

All photovoltaic solar cells transmit photons with energies below the absorption threshold (bandgap) of the absorber material, which are therefore usually lost for the purpose of solar energy conversion. Upconversion (UC) devices can harvest this unused sub-threshold light behind the solar cell, and create one higher energy photon out of (at least) two transmitted photons. This higher energy photon is radiated back towards the solar cell, thus expanding the utilization of the solar spectrum. Key requirements for UC units are a broad absorption and high UC quantum yield under low-intensity incoherent illumination, as relevant to solar energy conversion devices, as well as long term photostability. Upconversion by triplet-triplet annihilation (TTA) in organic chromophores has proven to fulfil the first two basic requirements, and first proof-of-concept applications in photovoltaic conversion as well as photo(electro)chemical energy storage have been demonstrated. Here we review the basic concept of TTA-UC and its application in the field of solar energy harvesting, and assess the challenges and prospects for its large-scale application, including the long term photostablity of TTA upconversion materials.

\section{Introduction}

Photovoltaic solar energy conversion devices waste a major part of the incident energy, due to the requirement of a gap in the continuum of electronic states in the light-harvesting material, acting as an absorption threshold. For photon energies higher than this bandgap, the excess energy is converted into heat by thermalization of excited charge carriers, while light with sub-bandgap energies cannot be harvested at all. These effects dominate the fundamental losses of single-threshold photovoltaic (PV) devices, and restrain their conversion efficiency to $34 \%$ under the AM1.5G spectrum, or about $30 \%$ under a model $6000 \mathrm{~K}$ spectrum ${ }^{1-3}$ (Fig. 1).

While power conversion losses in low-bandgap materials such as germanium or crystalline silicon (c-Si) are dominated by thermalization, transmission of sub-bandgap light is dominant for bandgaps of greater than $1.3 \mathrm{eV}$, that is, for most thinfilm photovoltaic absorber materials and for all known oxidebased electrode materials of interest to photoelectrochemical energy storage. ${ }^{4,5}$ Even solar cells made from c-Si sacrifice a considerable part of the solar spectrum by transmission.

Sub-bandgap losses can be remedied by the application of photonic upconversion, whereby transmitted light is converted to light of higher energy, which can then be harvested by the cell and contribute to current generation. Based on detailed balance considerations it has been shown that upconversion can boost the maximum energy conversion efficiency to about $43 \%$ under one sun for a solar cell with a bandgap of $1.76 \mathrm{eV}$, and $>50 \%$ under solar concentration. ${ }^{6}$ Crystalline

$0^{a}$ Helmholtz-Zentrum Berlin für Materialien und Energie GmbH, Institute Silicon Photovoltaics, Kekuléstr. 5, D-12489 Berlin, Germany.

$0^{b}$ School of Chemistry, UNSW Sydney, NSW 2052, Australia. E-mail: timothy.schmidt@unsw.edu.au silicon cells could still reach about $38 \%$, although the potential gain is smaller than for the high-bandgap devices.

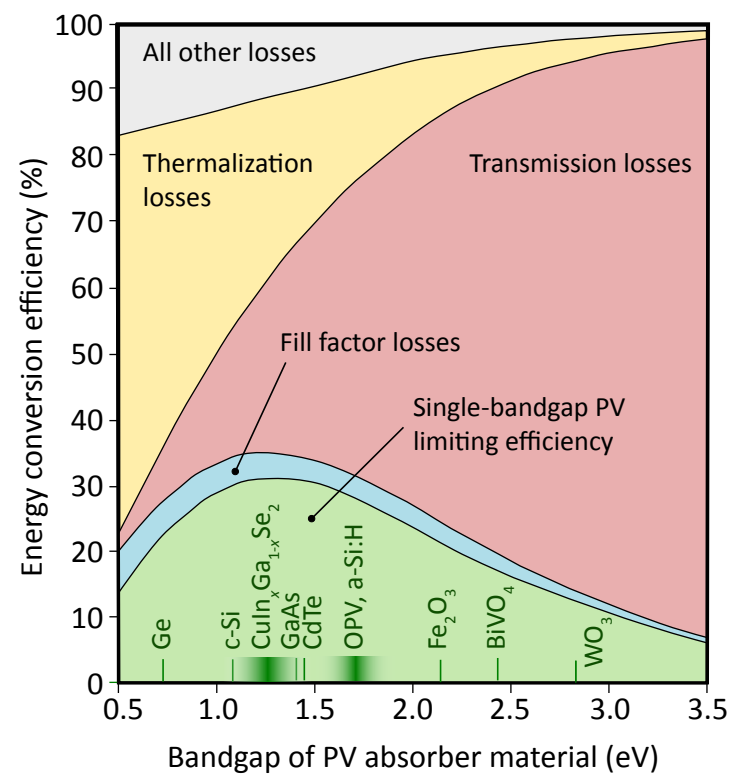

Fig. 1 Relative importance of fundamental loss mechanisms in solar energy conversion as a function of the PV absorber bandgap, and examples of absorber materials. Figure inspired by Hirst et. al. ${ }^{7}$, plotted for a $6000 \mathrm{~K}$ spectrum.

In recent years, upconversion has been an active area in the field of so-called 'third-generation photovoltaics' which comprises all thin-film device concepts that are, in principle, capable of circumventing the detailed balance efficiency limit (Shockley-Queisser limit ${ }^{1}$ ) for a single-threshold PV device. ${ }^{8,9}$ Research has focused mainly on two different and es- 


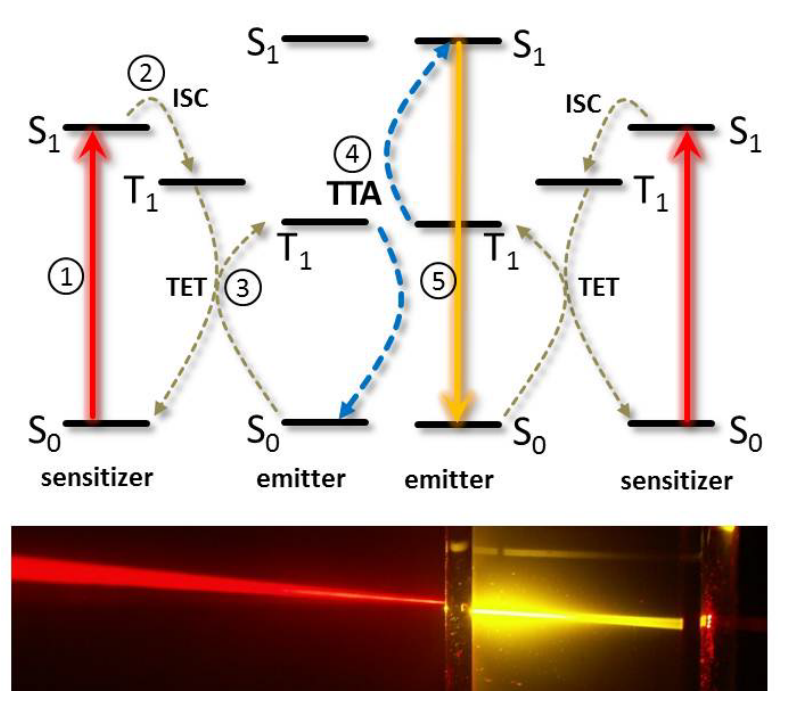

Fig. 2 Working principle of triplet-triplet annihilation upconversion (TTA-UC, top), and photograph of the TTA-UC effect (bottom). A key role is played by the long-lived triplet states $\mathrm{T}_{1}$ of the organic molecules which cannot decay quickly due to quantum-mechanical laws.

sentially complementary approaches: ${ }^{6,10}$ Firstly, the application of lanthanoid cations (mostly Erbium and Ytterbium) in a solid-state matrix ${ }^{11}$ making use of their discrete and longlived atomic states that can facilitate absorption of multiple photons, followed by upconverted luminescence. The rareearth materials absorb in the infrared region of the solar spectrum and lanthanoid upconversion (L-UC) is thus most interesting for application to c-Si solar cells ${ }^{12-14}$.

The second active field of research is the exploitation of triplet-triplet-annihilation in organic chromophores to achieve upconversion (TTA-UC). ${ }^{15-17}$ TTA-UC exploits the longevity of molecular triplet states. However, as the longevity diminishes with energy, TTA-UC is most readily applied to solar cells with bandgaps above about $1.5 \mathrm{eV}$. This review is devoted to summarizing the state-of-the-art in TTA-UC and its application to solar energy conversion.

\section{Triplet triplet annihilation upconversion: Po- tential and limits}

\subsection{Description of TTA-UC systems}

2.1.1 Working principle of TTA-UC. Upconversion by triplet-triplet annihilation requires a bimolecular system, consisting of an emitter molecule undergoing efficient TTA, and a sensitizer molecule which serves to absorb the incident light and create triplet excitations which are fed into the emitter manifold. It is based on the anti-Stokes delayed fluorescence first reported by Parker and Hatchard in the 1960s. ${ }^{18,19}$ The upconversion process is as follows: Sensitizer molecules absorb low energy photons (Step 1 in Fig. 2) and undergo intersystem crossing (ISC, Step 2) to their lowest triplet state. Ensuing fast triplet-triplet energy transfer (TET, Step 3) stores this energy in the lowest triplet state of emitter molecules. Two emitters then interact, facilitating triplet-triplet annihilation (TTA, Step 4), which ideally brings about one emitter molecule in an excited singlet state while the other is quenched to its ground state. More detail on the TTA mechanism is given below. The excited emitter in its $\mathrm{S}_{1}$ state immediately fluoresces (Step 5) at a higher energy than that of the photons initially absorbed.

TTA-UC exploits the strong oscillator strength of singletsinglet transitions to absorb and emit the light, while intermediate energy storage (necessary in incoherent UC processes as the energy of two photons, incident at different times, is merged) is facilitated by long-lived $\mathrm{T}_{1}$ triplet states. This represents an inherent advantage as compared to upconverting lanthanoid-based phosphors, which use the same electronic manifold to absorb, store and re-emit the photon energy, leading to low absorptivity and inherent competition of non-radiative losses with the UC process. Consequently, high upconversion yields, where $>30 \%$ of absorbed photons give rise to emitted photons, have been measured for TTA-UC. ${ }^{17,20}$

TTA-upconversion is an incoherent process, and the intrinsic intermediate energy storage in the triplet states allows for its efficient operation under low-light conditions. There are examples of lanthanoid upconversion proceeding efficiently under broadband, pulsed supercontinuum radiation, ${ }^{21,22}$ but several studies have shown TTA-upconversion under broadband white-light illumination, ${ }^{23,24}$ with some demonstrations even employing sunlight itself as the excitation source. ${ }^{25,26}$

2.1.2 Components of a TTA-UC system. The main requirements regarding the active molecules are:

i) A sensitizer species with

- a strong absorption in the desired region (peaking at several $\AA^{2}$ absorption cross-section),

- a high intersystem crossing yield, usually obtained by incorporating a heavy metal atom $\left(\Phi_{I S C} \sim 1\right.$ is desirable),

- a long triplet lifetime ( $>10 \mu \mathrm{s})$, and

- ideally a small singlet-triplet gap (few $k_{B} T$ ) so as to minimize energy sacrifice in the process of intersystem crossing.

ii) An emitter species with

- a long triplet lifetime ( $>100 \mu \mathrm{s})$,

- a singlet state at just below double the energy of the first triplet, to make TTA energetically favourable, and 
- a high fluorescence quantum yield $\left(\Phi_{F} \sim 1\right.$ is desirable).

Additionally, it is beneficial if the second excited triplet state of the emitter cannot be accessed by combining the energy of two sensitizer triplet states, as this would open a loss channel (see section 2.2). ${ }^{27}$

Commonly employed molecular species for TTA-UC systems are metallated porphyrins as sensitizers while polycyclic aromatic hydrocarbons (PAHs, for example rubrene, anthracene, perylene etc.) are the most commonly used emitters. However, efficient TTA-UC is not restricted to these classes of molecules, as others can also satisfy the abovementioned conditions: Transition metal complexes such as $\operatorname{Ir}(\text { ppy })_{3}{ }^{28}$ or $\mathrm{Ru}(\mathrm{dmb})_{3}{ }^{29}$ also facilitate efficient ISC by incorporating a heavy atom and can act as triplet sensitizers. Borondipyrromethene derivatives (so-called BODIPY dyes) ${ }^{30}$ were found to function as rare-metal-free triplet sensitizers at reasonable efficiency, and can also be combined with Ir complexes $^{31}$ to increase their absorption strength. Regarding emitter species, most studies have focussed on PAHs, with BODIPY- and conjugated polymer-based emitters being notable exceptions. ${ }^{16,32}$ Comprehensive review articles regarding the plethora of molecular species employed in TTA systems include the works of Singh-Rachford et al. ${ }^{16}$ and Zhao et al. ${ }^{17}$.

The large variety of molecules that satisfy the conditions outlined above allows for tailored spectral tuning of the absorption and emission wavelengths exhibited by the TTA system. So far, obtainable excitation wavelengths range from the blue $(440 \mathrm{~nm})^{33}$ across the visible ${ }^{16}$ and down into the near infrared (NIR) out to $>800 \mathrm{~nm},{ }^{34,35}$ while emission wavelengths of the upconverted light range from the deep red $(720 \mathrm{~nm})$ as far up as the near ultraviolet (NUV) at about $360 \mathrm{~nm} .{ }^{33,34}$ The obtained upconversion margins (that is, the energetic difference between peak absorbed and emitted light) range from $0.3 \mathrm{eV}^{36}$ to $1 \mathrm{eV}^{37}$, with typical values being around $0.5 \mathrm{eV}$.

\subsection{Dynamics and efficiency of homogeneous solution- based TTA systems}

The simplest realization of a TTA-UC system is obtained by the dissolution of the active molecules in a suitable solvent. Most of the fundamental studies on TTA dynamics, as well as the first device applications of TTA-UC, were based on this architecture. Commonly employed solvents are toluene, benzene, chloroform, acetonitrile, dimethylformamide or 1,1,2trichloroethane, among others.

In order to assess the efficiency of the TTA-UC process, two aspects have been considered in detail: Firstly, the sensitivity of the desired energetic pathways, sketched in Fig. 2, to unwanted relaxation/back-reaction processes such as the non-radiative loss of triplet excitons, phosphorescence and reverse intersystem crossing, and secondly, the details of the spin physics underlying the actual triplet-triplet annihilation process between two excited emitter molecules. Both aspects will be discussed in the following.

2.2.1 Rate equations. To describe the competition between the various molecular processes, and the resulting dynamics of the TTA systems, rate equations have been employed, ${ }^{27,38-42}$ which have the following general form:

$$
\begin{aligned}
\frac{d\left[{ }^{3} S^{*}\right]}{d t}= & k_{\phi}\left[{ }^{1} S\right]-k_{1}^{S}\left[{ }^{3} S^{*}\right]-k_{T E T}\left[{ }^{3} S^{*}\right]\left[{ }^{1} E\right] \\
& -k_{2}^{S E}\left[{ }^{3} S^{*}\right]\left[{ }^{3} E^{*}\right]-k_{2}^{S S}\left[{ }^{3} S^{*}\right]{ }^{2}=-\frac{d\left[{ }^{1} S\right]}{d t}(1) \\
\frac{d\left[{ }^{3} E^{*}\right]}{d t}= & k_{T E T}\left[{ }^{3} S^{*}\right]\left[{ }^{1} E\right]-k_{1}^{E}\left[{ }^{3} E^{*}\right] \\
& -k_{2}^{S E}\left[{ }^{3} S^{*}\right]\left[{ }^{3} E^{*}\right]-k_{2}^{E E}\left[{ }^{3} E^{*}\right]^{2}=-\frac{d\left[{ }^{1} E\right]}{d t}(2)
\end{aligned}
$$

Here, $\left[{ }^{3} S^{*}\right]$ and $\left[{ }^{3} E^{*}\right]$ are the sensitizer (S) and emitter (E) triplet populations, with $\left[{ }^{1} S\right]$ and $\left[{ }^{1} E\right]$ being the respective ground state populations. The rate constants are $k_{\phi}$ for the sensitizer excitation rate by absorption of incident photons, $k_{1}^{S}$ for the sensitizer triplet decay rate (incorporating phosphorescence and non-radiative decay), $k_{T E T}$ for the triplet energy transfer rate between the sensitizer and emitter manifold, $k_{1}^{E}$ for the non-radiative relaxation of emitter triplets, $k_{2}^{S E}$ for the hetero-TTA rate between sensitizer and emitter triplets, $k_{2}^{S S}$ for the homo-TTA rate between sensitizers, and $k_{2}^{E E}$ for the homoTTA rate between emitters. It is assumed here that hetero-TTA depletes both the sensitizer and emitter triplet populations. This may not be so, as the event may populate a singlet or triplet excited sensitizer level which will return the triplet sensitizer. However, in a well-designed TTA-UC system, these events should be rare compared to emitter homo-TTA.

Some of the processes depicted in Fig. 2 are not explicitly accounted for in the rate equations, such as the photoexcitation to the sensitizer singlet $S_{1}$ and the intersystem crossing to $T_{1}$, which are assumed to have unit efficiency and be relatively instantaneous. Indeed, intersystem crossing (ISC) in the $\mathrm{PQ}_{4} \mathrm{Pd}$ sensitizer used in much of our work proceeds with a time constant of approximately $10 \mathrm{ps}$. The prepared singlet state would otherwise radiate with a lifetime of some nanoseconds, and as such it can be seen that the ISC yield is near unity.

Typical values for the rate constants are listed in Table 1, assuming a slowly diffusing sensitizer and a rapidly diffusing emitter such as those studied by Castellano and coworkers. ${ }^{38,43}$

2.2.2 Spin physics and triplet balance. A crucial aspect of the TTA-UC process is the triplet-triplet-annihilation itself, 
Table 1 Typical kinetic parameters for a TTA-UC system operating under one sun.

\begin{tabular}{lrlr}
\hline Quantity & Value & Unit & Reference \\
\hline$k_{\phi}$ & 4 & $s^{-1}$ & {$[39]$} \\
$k_{1}^{S}$ & $2.5 \times 10^{4}$ & $s^{-1}$ & {$[39]$} \\
$k_{1}^{E}$ & $1 \times 10^{4}$ & $s^{-1}$ & {$[39]$} \\
$k_{T E T}$ & $1 \times 10^{9}$ & $M^{-1} s^{-1}$ & $a$ \\
$k_{2}^{S E}$ & $1 \times 10^{9}$ & $M^{-1} s^{-1}$ & $a$ \\
$k_{2}^{S S}$ & $1 \times 10^{8}$ & $M^{-1} s^{-1}$ & {$[39]$} \\
$k_{2}^{E E}$ & $2 \times 10^{9}$ & $M^{-1} s^{-1}$ & {$[38,43]$} \\
\hline$a$
\end{tabular}

${ }^{a}$ In the case of a slowly diffusing sensitizer, the hetero-TTA rate will be approximately half that of the emitter homo-TTA rate, and similar to the triplet energy transfer rate.

which fundamentally determines the obtainable efficiency of the overall process. When two emitter molecules in their respective triplet excited states $\left({ }^{3} \mathrm{E}^{*}\right)$ interact and form an encounter complex, it can be of singlet, triplet, or quintet multiplicity, as a consequence of the tensor product of the initial spin states of the molecules.

$$
{ }^{3} E^{*}+{ }^{3} E^{*}\left\{\begin{array}{l}
\rightleftharpoons{ }^{1}|E \cdots E|^{*} \rightarrow{ }^{1} E+{ }^{1} E^{*} \\
\rightleftharpoons{ }^{3}|E \cdots E|^{*} \rightarrow{ }^{1} E+{ }^{3} E^{* *} \\
\rightleftharpoons{ }^{5}|E \cdots E|^{*} \rightarrow{ }^{1} E+{ }^{5} E^{*}
\end{array}\right.
$$

Due to the degeneracies of the spin states, the complex formation probabilities are statistically weighted with regard to their multiplicity. That is, in the ratio of $1: 3: 5$, respectively. Only the singlet complex ( 1 in 9) can dissociate to the emitter $S_{1}$ state $\left({ }^{1} E^{*}\right)$ and thus yield the desired upconverted fluorescence (pathway from Eq. 3).

For a time it was unclear whether these spin statistics fundamentally limited the efficiency of the TTA-UC process and thereby constrained its applicability to solar cells. Some studies claimed a fundamental limit of $11 \%$ emitter $S_{1}$ yield based on this statistical argument, which would correspond to a maximum 5.5\% quantum yield of the upconversion process, disregarding any other losses. ${ }^{36}$ However, it had already been observed in organic light emitting diodes that triplet-triplet annihilation could bring about excited singlet states with an efficiency exceeding the statistical limit, ${ }^{44}$ and this simple argument has been dismissed based on energetic considerations: ${ }^{27,32,44,45}$ The emitter quintet state $\mathrm{Q}_{1}$ always lies above the lowest excited singlet state $\left(\mathrm{S}_{1}\right)$ and above the lowest excited triplet state $\left(\mathrm{T}_{1}\right)$, and, for the vast majority of candidate emitter molecules, $\mathrm{Q}_{1}$ is energetically inaccessible by combining their $\mathrm{T}_{1}$ states. ${ }^{46}$ This means that the quintet channel (Eq. 5) is never open, and a quintet encounter complex must dissociate back to the two initial emitter triplets without loss of stored energy.

The question, then, becomes whether or not the triplet channel is open (Eq. 4). If it is, then the respective TTA process will create an emitter in its second excited triplet $\left({ }^{3} E^{* *}\right)$, which will rapidly internally convert to the first excited triplet state $\left({ }^{3} E^{*}\right)$ following Kasha's rule. Therefore, this process would recover one of the initial triplets, meaning that five emitter triplets would be quenched for every emitted photon (taking into account the spin statistical ratio of 1:3 between the singlet and triplet channels), corresponding to a quantum yield of $20 \%$. The fact that several studies have observed quantum yields exceeding this number shows that there must be systems in which ${ }^{3} E^{* *}$ is inaccessible. Currently, the highest reported TTA quantum yields are above $30 \%$ in solution, ${ }^{27}$ effectively ruling out full participation of the triplet channel.

The rate at which photons are generated in the TTA-UC process, per unit volume irradiated, is at most $0.5 \times k_{2}^{E E}\left[{ }^{3} E^{*}\right]^{2}$, where it is assumed that each two triplets lost will yield a photon, that is, that both the triplet and quintet channels are closed. We introduced the factor $\eta_{\text {conv }}$ to express the probability that the loss of a pair of triplets yields a photon by the bimolecular process. In rubrene, this was found to be about $\eta_{\text {conv }}=0.6 .^{27}$ For an operational triplet channel, we expect that one excited singlet is produced for each five triplets lost giving $\eta_{\text {conv }}$ of 0.4 (five triplets is 2.5 pairs). Finally, we need to consider that the excited singlet state may not decay radiatively, and so the fluorescence quantum yield, $\Phi_{F}$, should be considered. As such, we arrive at the expression for the rate of photon output by TTA-UC per unit volume irradiated, $W_{T T A}=0.5 \times \eta_{\text {conv }} \Phi_{F} k_{2}^{E E}\left[{ }^{3} E^{*}\right]^{2}$.

2.2.3 Intrinsic behaviour of TTA systems. One may examine the rate equations (Eqns. 1-2) with realistic numbers for a typical liquid TTA system, to discern the crucial steps of the process. Table 1 shows the numbers obtained in various kinetic studies, including $\mathrm{PQ}_{4} \mathrm{Pd}$ :rubrene in toluene which is a red-absorbing system applicable to thin-film solar cells. ${ }^{47}$ It is instructive to plot the steady-state photon output, which is proportional to the square of the steady-state emitter triplet concentration, $\left[{ }^{3} E^{*}\right]^{2}$, as well as the TTA-UC quantum yield, which is given by $\eta=W_{T T A} /\left(k_{\phi}\left[{ }^{1} S\right]\right)$. The plots are shown in Fig. 3 for two sets of molecular concentrations (black: sensitizer concentration $1 \mathrm{mM}$, emitter concentration $10 \mathrm{mM}$, representing the solubility limit of both species in toluene; red: sensitizer concentration $10 \mathrm{mM}$, emitter concentration $100 \mathrm{mM}$ ). The shaded region highlights the range of excitation rate which is attainable under sunlight for common porphyrin sensitizer species with Q-band absorption cross sections peaking around $\sigma=1-5 \times 10^{-16} \mathrm{~cm}^{2}$, and a bandwidth of about $50 \mathrm{~nm}$.

The model reproduces the prototypical intensity behaviour of TTA systems under variation of the illumination, seen in many experiments: ${ }^{40,41}$ A quadratic increase of the photon output for low illumination density, saturating into a linear regime for high illumination conditions. The quantum yield 


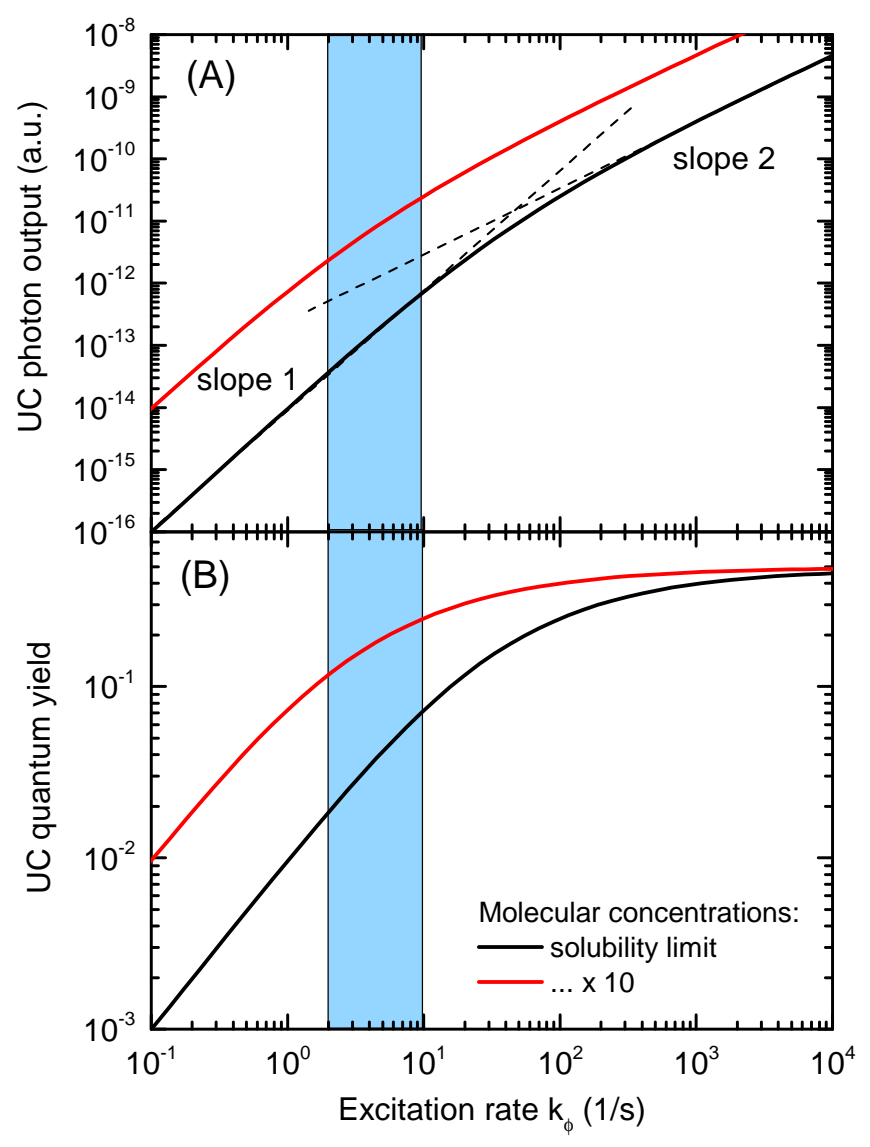

Fig. 3 Solutions of the TTA rate equations for typical rate constants at the solubility limit (black curve), as well as for 10-fold increased molecular concentrations (red curve). The blue area marks the range of sensitizer excitation rate attainable under sunlight illumination.

linearly increases for small $k_{\phi}$, and begins to saturate in the transition region between the quadratic and linear photon output regimes. The transition from quadratic to linear behaviour has been characterized by Monguzzi and co-workers as the threshold intensity, $I_{t h} .{ }^{40}$ This behaviour correlates with that observed for rare-earth upconversion, where the efficiency increases linearly in the low-pump regime and rolls over to sublinear and saturates under high pumping conditions. ${ }^{48}$

In the present case, no spin-physical limitations and no further hindrances to the operation of the system have been assumed $\left(\eta_{c o n v}=\Phi_{T T A}=1\right)$, therefore the quantum yield saturates at the physical maximum of 50\%. It is easy to see that for operation under sunlight illumination, the given TTA system is inefficient. The quantum yield for $k_{\phi}=4 \mathrm{~s}^{-1}$, which was measured for $\mathrm{PQ}_{4} \mathrm{Pd}$, is around 3-4\%, even in the solubility limit of $\mathrm{PQ}_{4} \mathrm{Pd}$ and rubrene in toluene (black curve).

In order to increase the quantum yield to applicationrelevant levels, the model suggests two strategies: Increasing the concentration of active species, and/or increasing the illumination density. If it were possible to increase $[E]$ and $[S]$ by a factor of 10 at constant rates (red curve), the quantum yield increases significantly to around $20 \%$. To this end, overcoming the solubility limit is the prime goal, which is currently being pursued mainly by solid-state approaches to TTA materials. These are to be discussed in the next section. Other approaches aiming at increasing molecular concentrations as well as ideas to (locally) increase the excitation rate will be covered in Section 4.

\subsection{Towards solid-state TTA}

So far, the most widely followed approach to creating solidstate TTA-UC materials is the blending of the active species into a photophysically inert polymeric host matrix, which serves as a mechanical support for the chromophores. It has been determined that a crucial requirement for the matrix material is a low glass-transition temperature as the bimolecular interactions leading to the TET and TTA events require some residual diffusivity. ${ }^{49}$ Consequently, most of the reported systems are based on soft 'rubbery' polymers. Up to now, TTA-UC has been demonstrated in several host matrices including, but not limited to, cellulose acetate, ${ }^{50}$ polystyrene, ${ }^{51}$ a copolymer of ethyleneoxide and epichlorohydrin, ${ }^{49,52}$ polyurethane, ${ }^{53,54}$ or poly-butylacrylate. ${ }^{55}$ It was further shown that upconverting nanoparticles can be formed using the blending approach with different polymeric host media, including polystyrene ${ }^{56}$ or poly-butylacrylate. ${ }^{57} \mathrm{Con}-$ cerning the attainable efficiency of such blended solid-state systems, aggregation or even phase-segregation of the dye species, at concentrations above a few percent, has been found to be a serious issue which has so-far prevented the realization of higher UC quantum yields as compared to the liquid systems. ${ }^{58}$

A strategy that might help to overcome part of this problem is the use of a polymer host which, at the same time, acts as the TTA emitter species, and is doped with only one triplet sensitizing species. Several groups have investigated these materials, including porphyrin-doped polyfluorene ${ }^{59}$, porphyrindoped poly-pentaphenylene ${ }^{60}$ and porphyrin-doped superyellow. ${ }^{32}$ Again, in most cases the aggregation of the porphyrin triplet sensitizers appeared to be a major problem.

To summarize the state-of-the-art in solid-state TTA-UC it can be said that although fairly efficient TTA-UC has been demonstrated in the solid phase by the blending approach (up to $17 \%$ quantum yield ${ }^{55}$ ), this strategy will most likely not allow much higher quantum yields than the liquid approach without a precise and tailored control over the microscopic arrangement of the active species in order to prevent aggregation and phase separation. The reader is referred to the review article of Simon and Weder, who discuss the pending issues in 
great detail. ${ }^{58}$ Strategies that might allow such control will be discussed below in Section 4.2.3.

\section{Application of TTA in solar energy conver- sion}

\subsection{Approaches for harvesting sub-bandgap light}

Since the early beginnings of photovoltaic energy conversion research it has been clear that sub-bandgap transmission is among the two most severe fundamental efficiency losses. ${ }^{1}$ Thus, the challenge of harvesting sub-bandgap light has stood for decades. Several approaches, aimed at circumventing these losses, have been proposed and, in part, realized in devices. These are depicted in Fig. 4.

\subsubsection{Multijunction solar cells.}

The only approach which is presently widely used in PV technology is the concept of multi-junction cells (A in Fig. 4), which relies on the stacking of solar cells with different absorption thresholds. The first dual-junction solar cell (tandem) was based on AlGaAs/GaAs and presented in 1979 during a brief period of intense PV research fueled by the 1970s oil crisis. ${ }^{61}$ Over the successive decades, tandems and multijunctions were developed further, with interest in the GaAs system being renewed in the 1990s by the DoE's Concentrator Initiative Program. Further performance steps were the first triplejunction devices on germanium substrates ${ }^{62}$ in 2000, as well as the first quadruple-junction cell in 2013, which holds the current record for PV energy conversion under concentrated light (44.7\% under 297 suns). ${ }^{63}$ Over the last 2-3 decades, thin-film tandem and triple-junction cells based on amorphous and microcrystalline silicon as well as on amorphous silicongermanium have been developed, ${ }^{64,65}$ which are operated under non-concentrated light. Indeed, thin-film devices cannot be operated under concentrated light.

Irrespective of the undoubtedly higher conversion efficiencies with respect to single-junction PV - culminating in the impressive $44.7 \%$ record - the vast majority of the multijunction cells struggle on the global PV market. One of the major drawbacks is the rather complex manufacturing, which requires series-connection of complete solar cells, each of which is a multilayer structure itself. Also, the series connection requires matching of the photocurrents delivered by the subcells, which puts additional constraints on device design and leads to less robust operation, as the solar altitude as well as atmospheric and environmental parameters impact the relative performance of the sub-cells. That said, these cells can operate under hundreds of suns and as such can tolerate manufacturing costs hundreds of times higher providing the concentrator system can be built for negligible cost.
3.1.2 Intermediate band solar cells. For the above reasons, alternative concepts for harvesting sub-bandgap light have been proposed. Already in 1960, the idea of deliberately introducing impurities, causing the appearance of a band of electronic states in the bandgap of silicon PV absorbers, was suggested $^{66}$ (B in Fig. 4). Although the initial idea was dismissed, based on the assumption that the potential benefit of this 'intermediate band,' regarding absorption, would be overcompensated by increased Shockley-Read-Hall recombination, $1,67,68$ it was later recognized that the positioning of the impurity band not at mid-gap but closer to one of the bands might increase the utilization of the solar spectrum and reduce the potential impact of recombination. ${ }^{69,70}$ However, no convincing realization of a so-called intermediate band solar cell (IBSC) in a bulk material has been demonstrated so-far.

Very recent research activities have focused on quantum dot arrays ${ }^{71}$ and highly mismatched alloys ${ }^{72}$ as potential realizations of multi-band IBSCs, with promising initial results. However, in order to design an economically competitive IBSC, the main drawback remains the necessity to electronically re-engineer the absorber material while at the same time preserving the excellent bulk electronic quality which has become state-of-the-art in PV technology.

3.1.3 Photonic upconversion. The third approach to circumventing sub-bandgap losses is photonic upconversion (panel $\mathrm{C}$ in Fig. 4). There are different physical mechanisms which can, in principle, achieve UC, among them coherent processes such as simultaneous two-photon absorption (STPA) and second-harmonic generation (SHG) which are not of interest to solar energy harvesting due to the requirement of coherent and intense illumination.

The most studied incoherent upconversion processes besides triplet-triplet annihilation (TTA) are energy transfer upconversion (ETU, also known as 'addition of photons by transfer of energy', APTE) and excited state absorption (ESA), which are observed for several classes of ions in solid-state matrices and were first reported by Auzel in $1966 .{ }^{73}$ Concerning ETU and ESA, the required long lifetimes of the respective excited states and a ladder-like arrangement of the energy levels with similar spacings are realized for certain ions of the $d$ and $f$ elements. Transition-metal ions with open $3 d, 4 d$ or $5 d$ shells have been reported to show upconversion in different host materials. The highest upconversion efficiencies realized to date for inorganic materials have been observed for solid matrices doped with lanthanoid ions, such as $\mathrm{Gd}^{3+}, \mathrm{Dy}^{3+}$, $\mathrm{Er}^{3+}, \mathrm{Yb}^{3+}$ or $\mathrm{Tm}^{3+}$. One of the most efficient UC phosphors to date is $\mathrm{NaYF}_{4}$, doped with $\mathrm{Er}^{3+}$ or co-doped with $\mathrm{Yb}^{3+}$ and $\mathrm{Er}^{3+}$, which was introduced in 1972 by Menyuk et al. ${ }^{74}$ Comprehensive reviews of ETU by $f$-shell ions in solid bulk matrices and nanoparticles include the works by Auzel ${ }^{11}$ and Haase et al. ${ }^{75}$ 


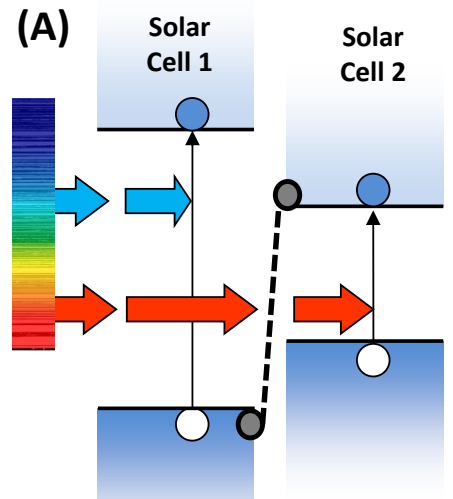

Tandem solar cell

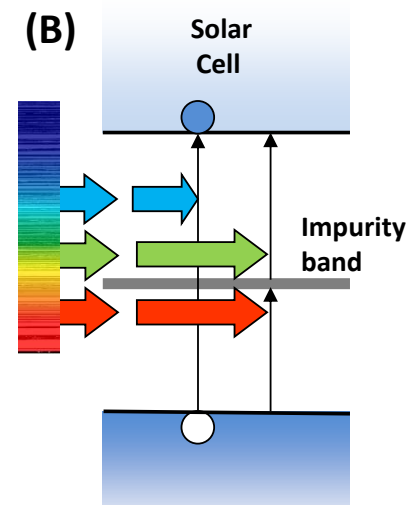

Intermediate band solar cell

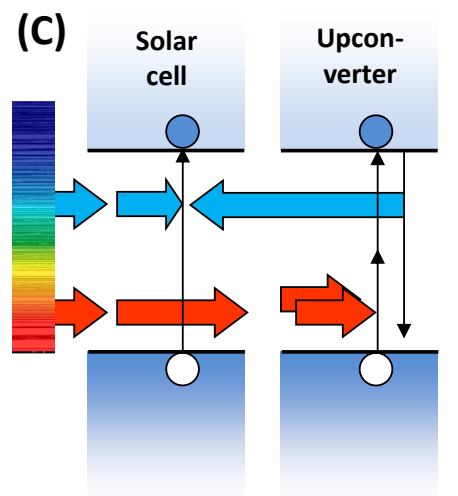

Photonic upconversion

Fig. 4 Fundamental concepts to circumvent sub-bandgap losses in PV devices. (A) Tandem solar cells, requiring the electrical connection of two sub-cells incorporating different absorber materials. (B) Introduction of an impurity band (or intermediate band) into the semiconductor absorber. (C) Photonic upconversion in a material placed behind the solar cell and re-radiation of the upconverted light towards the PV absorber.

The first realization of an upconversion-assisted solar cell was based on $\mathrm{Yb}^{3+}$ and $\mathrm{Er}^{3+}$ ions in a vitroceramic host, placed behind a GaAs solar cell. ${ }^{76}$ The first application of the same system to c-Si solar cells was demonstrated in 2005 by Shalav et al., ${ }^{13,77}$ and current lanthanoid-based upconversion efforts are mainly focused around crystalline silicon, ${ }^{14,78-80}$ due to the energetically favorable absorption of $\mathrm{Er}^{3+}$ around $1523 \mathrm{~nm}$, below the c-Si band edge in energy and within a local maximum of the solar spectral irradiance. ${ }^{12}$ Currently, the most efficient lanthanoid upconversion phosphor for c-Si PV applications appears to be $\beta-\mathrm{NaYF}_{4}: 20-25 \% \mathrm{Er}^{3+}$ powder. ${ }^{14,81,82}$ However, a very recent record result was obtained with mono-crystalline $\mathrm{BaY}_{2} \mathrm{~F}_{8}: 30 \% \mathrm{Er}^{3+}$, which indicates that there is still potential for further efficiency increase of lanthanoid-UC aiming at c-Si solar cells. ${ }^{83}$

Furthermore, also other types of solar cells have been assisted by lanthanoid-based upconversion: De Wild et al. have applied the $\mathrm{Yb} / \mathrm{Er}$ system to amorphous silicon solar cells, in the form of a $\mathrm{NaYF}_{4}:\left(18 \% \mathrm{Yb}^{3+}, 2 \% \mathrm{Er}^{3+}\right)$ phosphor, ${ }^{84,85}$ as well as in a more recent study employing a $\mathrm{Gd}_{2} \mathrm{O}_{2} \mathrm{~S}:\left(10 \% \mathrm{Yb}^{3+}, 5 \% \mathrm{Er}^{3+}\right)$ phosphor. ${ }^{86}$ Liu et al. have employed an yttrium-aluminium garnet (YAG) transparent ceramic co-doped with $3.0 \% \mathrm{Yb}^{3+}$ and $0.5 \% \mathrm{Er}^{3+}$ behind a dyesensitized solar cell (DSSC), ${ }^{87}$ while Shan et al. integrated $\mathrm{Er}^{3+}$ and $\mathrm{Yb}^{3+}$ co-doped into $\mathrm{LaF}_{3}$ in a nanocomposite with $\mathrm{TiO}_{2}$ to serve as upconversion layer in DSSCs. ${ }^{88}$ Other examples of lanthanoid-based upconversion applied to DSSCs include the employment of fluorescence resonance energy transfer from upconversion centres, ${ }^{89}$ the use of colloidal upconversion nanocrystals as an energy relay, ${ }^{90}$ and direct electron injection from up-conversion nanoparticles to the $\mathrm{TiO}_{2}$ pho- toanode. ${ }^{91}$ For a useful review on upconversion nanophosphors for solar cell applications, see the recent review of Ramasamy et al. ${ }^{92}$

In 2012, our group demonstrated the first solar cell assisted by triplet-triplet annihilation upconversion, using the example of an amorphous silicon thin-film solar cell. ${ }^{47,93,94}$ The approach was successively applied to organic solar cells ${ }^{95}$ as well as dye-sensitized solar cells. ${ }^{96}$ Details about these results and a comparison to the lanthanoid upconversion system are given below.

\subsection{Limiting efficiency for UC-enhanced solar cells}

There is general agreement that, regarding the maximum possible efficiency from an idealized thermodynamic perspective, upconversion-assisted solar cells are on par with tandem and intermediate band solar cells. Trupke et al. have calculated $47.6 \%$ maximum conversion efficiency for an upconversionassisted solar cell under non-concentrated sunlight ${ }^{9}$, using a detailed balance calculation based on equivalent circuits and assuming $6000 \mathrm{~K}$ blackbody radiation. Importantly, they considered an unconstrained model allowing for two different low-energy absorption thresholds, that is, the upconvertor was modeled equivalently to two low-bandgap bottom cells connected in series which drive an LED illuminating the highbandgap top cell. Tayebjee and Schmidt calculated a maximum efficiency of $48.2 \%$ for the same system using the actual AM1.5G solar spectrum as illumination source. ${ }^{6,97}$

Both ETU by lanthanoid ions and TTA-UC are based on the interaction of identical excited states - either within the $4 f$ manifold of the lanthanoid ions or of the first excited triplet state of the TTA emitter species - which restricts the detailed 
balance model to a symmetrical case. Tayebjee and Schmidt have calculated a limiting efficiency of $43.3 \%$ for this case, with an optimum solar cell absorption threshold of $1.76 \mathrm{eV}$ and an upconvertor absorption threshold of $1.11 \mathrm{eV} .^{6,97}$

For comparison, within the same modeling approach, tandem solar cells, symmetric IBSCs and asymmetric IBSCs were found to have limiting efficiencies of $45.7 \%, 45.9 \%$ and $51.9 \%$ respectively. It has been determined that the luminescent coupling to the 'top cell' PV device brought about by the UC approach is slightly inferior to the direct electrical coupling manifested in tandems or IBSCs, due to an additional free energy sacrifice by the re-emission process. Indeed, Schmidt and Ekins-Daukes proposed that direct injection by emitters acting as dyes in DSSCs would in effect be a symmetric IBSC - a molecular intermediate band solar cell. ${ }^{98} \mathrm{On}$ the other hand, and unlike for tandems and IBSCs, a radiatively coupled upconvertor does not interfere with the electronic structure of the absorber and the electrical layout of the solar cell, which makes it much easier to implement into current PV technology.

Recently, modeling work has been undertaken in order to assess the limiting efficiency of solar cell/UC couples under more realistic boundary conditions. Johnson and Conibeer have analyzed non-ideal c-Si solar cells coupled to ideal UC units, and their results are quite specific to crystalline silicon $\mathrm{PV}^{99}$. Atre and Dionne have attempted to formulate a model for upconversion-assisted solar cells incorporating nonidealities such as recombination in solar cell and upconvertor, non-radiative relaxation within the upconvertor, narrow absorption bands of the UC materials as well as non-ideal absorption of solar cell and upconvertor. ${ }^{100,101}$ They also explicitly include the characteristics of real UC systems from the domains of both TTA and lanthanoids. Due to the plethora of parameters in the respective model a rather complex picture emerges, but the general conclusions are that high-bandgap thin-film PV technologies are most interesting for combining with UC, and that 'bimolecular upconverting materials are already well-suited to enhance the efficiency of high-bandgap devices by almost one absolute percent'. ${ }^{101}$

\subsection{Design considerations of TTA upconversion systems}

Before discussing the results achieved to date in applying TTA-upconversion to solar cells and photochemical solar energy storage devices, we outline the general design principles of TTA-UC systems for solar energy applications below.

3.3.1 Energetic considerations. The energetic structure of the TTA system defines the upconversion margin, that is, the difference in energy between the absorbed and emitted light. While this does not a priori affect the obtainable current increase in combination with a solar cell, it has an indirect impact: Usually, the quantum efficiency of a solar cell drops

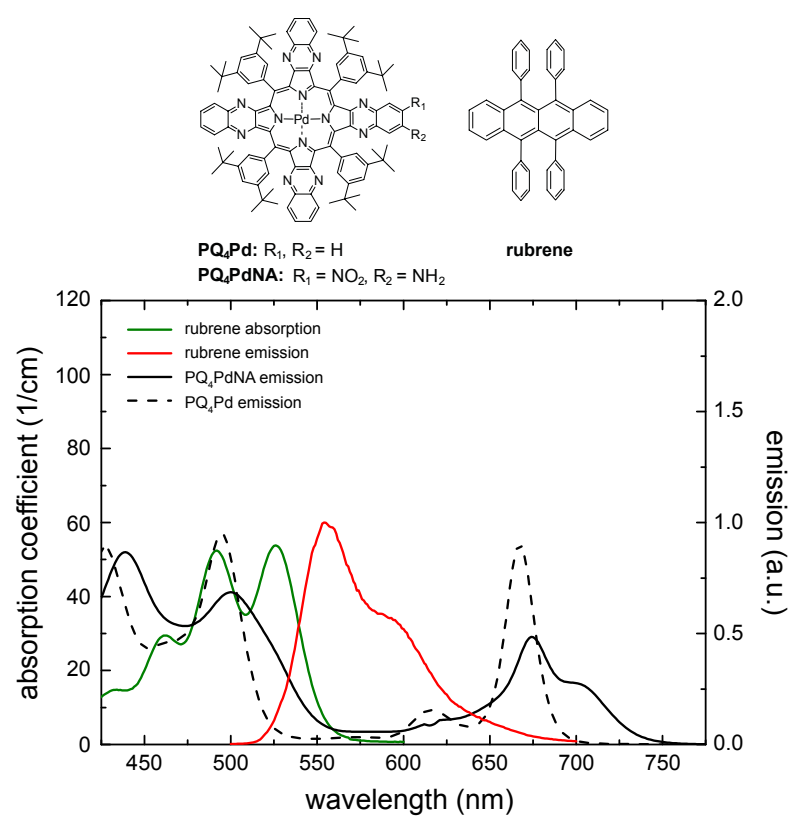

Fig. 5 Absorption and emission spectra for a typical TTA-UC system $\left(\mathrm{PQ}_{4} \mathrm{Pd}(\mathrm{NA})\right.$ at $0.5 \mathrm{mM}$ and rubrene at $5 \mathrm{mM}$ dissolved in toluene). There is a slight overlap of the rubrene emission band with its own absorption band (resulting in self-absorption) as well as with the $\mathrm{PQ}_{4} \mathrm{Pd}(\mathrm{NA}) \mathrm{Q}$ - and Soret bands.

towards the absorber band edge, and it therefore makes sense to choose the upconvertor so as to emit further into the absorption band, to allow the PV cell to make best use of the upconverted photons. Further, with a higher upconversion margin, more sub-bandgap light may be harvested, and upconverted to above the absorption threshold.

As seen in Fig. 2, there are energy losses associated with ISC and there may be energy losses in the TET and TTA processes. ${ }^{37}$ The largest contribution to the overall energy loss usually stems from intersystem crossing, as the singlet-triplet gaps of common sensitizer species are in the order of $0.4 \mathrm{eV}$. The triplet energy transfer between the sensitizer and emitter manifold is driven by a free energy gradient, and so does not necessarily rely solely on an enthalpic difference between sensitizer and emitter triplets. Indeed, a difference in concentration between the two species can be exploited to drive TET via the entropic gain associated with the exciton transfer from the smaller reservoir of states in the sensitizer manifold to a larger reservoir among the emitter species. ${ }^{37}$ It has to be noted, though, that the overall efficiency of the TTA process is affected if TET is endergonic. TTA itself is not necessarily associated with an energy loss either, as a careful choice of the emitter species allows the energy of the $S_{1}$ singlet to be at twice the triplet energy $T_{1}$. But, a small energy sacrifice can help mitigate the effects of singlet fission reversing the 
TTA process. Providing the emitter demonstrates delayed fluorescence by TTA, the non-radiative decay rate of the emitter triplet states has a more direct impact on the overall efficiency.

3.3.2 Optical considerations. The main optical concerns are the width of the sensitizer absorption bands, parasitic absorption within the TTA system and the outcoupling efficiency of the upconverted light.

Typical widths of the main molecular absorption band of common sensitizer species (for example, the Q-band of a porphyrin) are around $50 \mathrm{~nm}$, which constrains the region within the solar spectrum that can be upconverted with a single TTA system. However, it has already been demonstrated that a family of sensitizers can be combined with a single emitter species in such way that the sensitizer absorption bands are staggered in order to provide a quasi-continuous absorption band over more than $125 \mathrm{~nm}$ width. ${ }^{102,103}$

In order to minimize parasitic absorption, the overlap between the emission band of the TTA emitter and the absorption bands of both emitter and sensitizer must be minimized. Figure 5 shows the situation for two TTA solutions employed in our studies, ${ }^{47,93,95}$ plotted for typical concentrations. It can be seen that there are slight overlaps between the rubrene emission and its own absorption band (self-absorption) as well as with the porphyrin sensitizer Q- and Soret bands. In the given situation, the characteristic decay length of the absorbed light due to sensitizer absorption is on the order of some $100 \mu \mathrm{m}$, while the baseline absorption of the porphyrin around the emitter peak emission wavelength is close to negligible. However, we note that upon shifting the absorption band of the $\mathrm{PQ}_{4} \mathrm{Pd}$ porphyrin further into the NIR by adding nitro- and amino-groups, resulting in $\mathrm{PQ}_{4} \mathrm{PdNA}$ (cf. Fig. 5), the baseline absorption slightly increases to $7000 \mathrm{M}^{-1} \mathrm{~cm}^{-1}$, about $10 \%$ of the peak absorbance in the red region of the spectrum. Similar effects were observed by Yakutkin et al. upon extending the $\pi$-system of a tetra-naphthaloporphyrin to bring about a tetra-anthraporphyrin: While the distance between the Q- and Soret band was still favourably large, the baseline absorption increased to a level which might affect the suitability for application. ${ }^{35}$

Optical modeling of the system shown in Fig. 5, as well as experiments with varying thickness of the UC unit, revealed that a TTA-UC layer in the presence of a rear reflector yields the highest overall photon output at a thickness which is roughly the characteristic decay length of the incident light at the peak absorption wavelength. ${ }^{47,104}$ This shows that the optics are dominated by absorption of the incident light and that parasitic absorption of the emitted light cannot play an important role as the ideal thickness would otherwise shift to lower values. Optical modeling predicts that a Lambertian back-scattering layer behind an UC layer of ideal thickness would enhance the UC photon yield by a factor of 3.6. A sim- ple specular mirror would improve the device by a factor of 2.6. ${ }^{47}$

In solution at $\mathrm{mM}$ concentrations, the porphyrin sensitizers employed in our studies require an optimum thickness of the active upconverting layer of between $50-150 \mu \mathrm{m}$. In a$\mathrm{Si}: \mathrm{H}$ and OPV systems, the absorber layer is on the order of 1000 times thinner. Eventually, it is desired to bring about upconverting layers of comparable thickness. Such a device will require nano-structured sensitizer supports and is the subject of present research. ${ }^{94}$ The requirement of realizing a TTA system with a thickness of around $100 \mu \mathrm{m}$ poses a challenge in combination with the necessity to rigorously deaerate the UC device in order to suppress triplet quenching by oxygen. The latter is usually achieved by sequentially freezing the TTA solution with liquid nitrogen, evacuating the volume over the frozen solution to the $10^{-5}$ mbar range, and successive thawing (freeze-pump-thaw cycle). This procedure requires a mechanically stable cuvette, which is not easily available with a $100 \mu \mathrm{m}$ gap. In our first UC-enhanced solar cell device, we placed a $1 \mathrm{~cm}$ diameter cuvette behind the solar cell which was optically connected to the cell by means of immersion oil. ${ }^{47}$ This arrangement has several drawbacks. Firstly, about half of the upconverted light is lost as it is emitted away from the solar cell and secondly, the cell itself suffers from very poor light-trapping without any back reflector.

In the next realization of the UC unit we implemented a crude back-scatterer comprising $100 \mu \mathrm{m}$-diameter silvercoated glass spheres, which were introduced into the $1 \mathrm{~cm}$ diameter cuvette. ${ }^{93}$ The effect of the resulting textured surface was to multi-pass the incoming light to improve absorption, while also improving the out-coupling of upconverted light. Indeed, with a close-packed structure of $100 \mu \mathrm{m}$ spheres, most of the surface area presents an optical depth less than this value. Nevertheless, most of the light rays impinging on the spheres are reflected at oblique angles. The solution to the ray-tracing equations required to model this device are complicated, yielding fractal patterns of reflections. ${ }^{105}$ The region between three spheres represents a so-called fractal vortex, with multiple reflections ensuring complete light absorption. The remainder of the illuminated volume can out-couple the upconverted light in at most one refection. With this topology inside a standard $1 \mathrm{~cm}$ diameter cuvette we realized a twofold increase of the UC-related current increase as compared to the quasi-infinite case. ${ }^{93}$ The comparison to the optical modeling results ${ }^{47,104}$ shows that the configuration is not optimal, but reasonably close to the optimum situation. At the same time it allows for facile freeze-pump-thaw deaeration which led us to adapt this configuration to be the standard experimental setup.

Nonetheless, we fabricated a custom 'half cuvette' which directly connects to the backside glass sheet of the solar cell and allows for a continuous variation of the upconvertor thickness, for further studies of the UC optics. ${ }^{104}$ Additionally, dif- 
ferent reflectors can be employed and compared in an in-situ experiment. With this device we validated the optical modeling regarding the optimal thickness of the UC layer and could show, for the first time, that local concentration of the incident light leads to an additional enhancement of the UC yield. These results will be discussed in Section 4. Based on the results obtained, regarding optimum UC layer thickness and reflectors, we finally employed a device-integrated cavity at the correct thickness, incorporating a dielectric reflecting backside layer, which was integrated into a dye-sensitized solar cell. ${ }^{96}$ Details are given below in Section 3.5.2.

3.3.3 Solar cell and systems considerations. For a maximum efficiency of the solar cell/upconvertor assembly, the solar cell needs to fulfil the following requirements besides a high overall efficiency: It must possess a high transmission in the wavelength region of the sensitizer absorption to pass as much of the unused light to the UC unit, as well as display a high quantum efficiency at the emission wavelength of the emitter to make best use of the upconverted light. While the general approach of UC-assisted solar cells should be to adapt the UC material to an existing high-efficiency solar cell instead of vice versa, it is in practice always required to partly adapt the solar cell to the UC material. This stems from the fact that most solar cells employ metallic back contacts, which need to be replaced by transparent conductive oxides (TCOs) or polymers, and most frontside TCOs and/or antireflection coatings (ARCs) are not optimized for high transmission in wavelength ranges outside the solar cell response. Detailed optical simulations have been performed in the domain of c-Si solar cells for the combination with lanthanoid materials, ${ }^{106}$ which led to improved performance of the overall assembly by mainly increased sub-bandgap transmission. We have also performed optical modeling and deliberately adapted our aSi:H solar cells for optimized overall optics (cf. section 3.6).

Given the finite absorption range of lanthanoid-based UC materials, strategies have been developed in order to increase the harvest of sub-bandgap light. One possibility would be to combine the UC material with a downshifting luminescent solar concentrator (LSC), as proposed within the so-called NanoSpec concept. ${ }^{107}$ The LSC would serve to both funnel more spectral weight of the solar spectrum into the UC absorption range and at the same time to geometrically concentrate the incident light, thus exploiting the non-linearity of the UC process for an increase of the quantum yield. As a side effect, the use of UC material would be reduced. While conceptually convincing, the main drawback currently lies in the low quantum efficiency of downshifting phosphors in the infrared range.

While the mentioned concept would in principle be applicable to TTA-UC materials as well, it appears more promising to employ combinations of multiple sensitizers whose com- bined absorption regions are staggered such that they straddle a larger region of the solar spectrum - a strategy first introduced by Baluschev et al., ${ }^{102,103}$ which was shown to work with a single emitting species if the energy levels are correctly aligned. Broadening the upconvertor's spectral response through sensitization with semiconductor nanocrystals has been attempted, but this introduces reabsorption of upconverted light at the expense of a back-reflector. ${ }^{108}$ Strategies towards realizing concentration of the incident light in combination with TTA-UC units will be discussed below in section 4.2.2.

\subsection{How to measure UC-assisted solar cells}

In order to verify the extended utilization of the solar spectrum by a solar cell, brought about by an attached upconvertor unit, the straightforward approach is to measure precisely the spectral response of the solar cell in the presence of the upconvertor and compare it to the situation without the UC effect. It turns out that this is a nontrivial task, for the following two reasons:

1. Usual spectral response or (external) quantum efficiency (QE) measurement schemes use monochromated white light as the (modulated) probe, which results in sensitizer excitation rates much below 1-sun operation conditions. As the response of the upconvertor, upon changing the illumination density, is nonlinear at low flux (cf. Fig 3), the net contribution of the upconvertor to the QE will be close to zero. Therefore, one has to use a detection and analysis scheme which takes into account the nonlinear nature of the upconversion process.

2. To deconvolute the contribution of the upconvertor from the solar cell characteristics, it is required to measure the solar cell with and without a contribution from the upconvertor. However, the upconversion unit comprises a reflector which is an integral part of the overall optical system and acts also for wavelengths outside the active region of the UC unit. Therefore, physically removing the upconversion unit will alter the optical behaviour of the solar cell and obstruct the interpretation of the measurement.

\subsubsection{Measurement scheme.}

In order to measure UC-enhanced thin-film solar cells, we have employed the following strategy: To compensate for the nonlinear response of the UC unit and the resulting negligible UC output at common probe beam intensities, we subject the upconvertor to a bias beam that selectively excites the sensitizer species. As opposed to the QE probe beam, which is chopped to allow for lock-in detection of the solar cell current, the bias beam is a continuous wave $(\mathrm{CW})$. Fig. 6 shows 


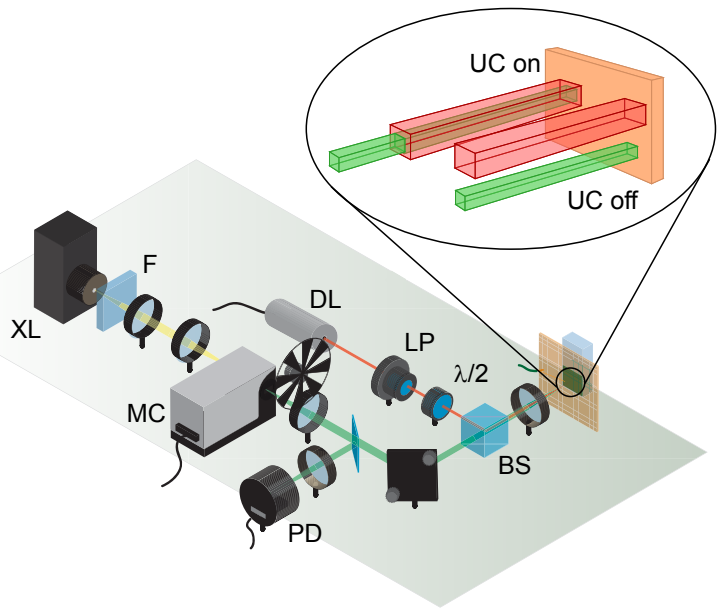

Fig. 6 Measurement scheme for solar cells enhanced by TTA-UC. A diode laser selectively pumping the sensitizer absorption but not disturbing the solar cell is used to bias the triplet concentration in the upconvertor unit, to allow for its measurement with a chopped monochromated white light probe as commonly employed in quantum efficiency measurements. The upconvertor is characterized by comparing the situation with the two beams aligned with those where the beams are misaligned, rendering the UC yield negligible. $\mathrm{XL}$ - xenon arc lamp, F - long-pass filter, MC - monochromator, BS beamsplitter, DL - diode laser, LP - linear polariser, $\lambda / 2$ - half-wave plate, PD - photodiode. Figure adapted from Reference 109.

the resulting setup for the measurement of UC-enhanced solar cells. The bias beam produces a constant background population of triplet-excited species in the upconvertor, which improves the likelihood of emitters, excited by the probe beam, finding annihilation partners. Thus, the $\mathrm{CW}$ beam positively biases the upconversion efficiency in order to create a measurable response of the UC unit. It is important to note that the bias beam should have a much higher power density as compared to the probe beam. However, it provides photons with an energy where the solar cell has close to zero absorption. Although the lock-in detection method would filter out an eventual DC contribution of the bias beam to the solar cell current, this ensures that the solar cell response is not saturated by the bias. Ideally, the laser bias takes the role of a moderate DC light bias for the solar cell, which is best practice for the QE measurement of thin-film solar cells. In cases where the solar cell had enough residual absorption in the wavelength range of the bias beam as to risk saturation effects, we ensured that probe and bias beam entered the setup from different angles in such way that they geometrically aligned on the upconvertor unit, but not on the active cell area.

The setup described above allows circumvention of the nonlinear response of the UC unit, but leaves us with the second challenge of how to compare the UC-augmented with the standard response of the cell. Regarding this issue we exploited the before-mentioned drawback: As the unbiased upconvertor shows negligible response upon illumination by the probe beam alone, we may take this situation to be the baseline for the QE measurement. However, just switching off the bias beam might again change the solar cell behaviour in cases where the cell absorbs slightly in the bias energy region and shows nonlinear effects - which cannot be excluded a priori. We therefore keep the bias beam switched on at all times, and misalign the two beams for the baseline measurement (Fig. 6). By doing this, the solar cell still sees the same overall DC bias illumination, but the upconvertor response in the geometrical region probed by the probe beam is negligible.

This measurement scheme is based on two assumptions: Firstly, any nonlinearity of the solar cell does not depend on the position of the illuminated spot, and secondly, the probe beam is sufficiently faint as to ensure a negligible UC response. The first assumption is usually fulfilled for wellbehaved solar cells, and can be easily tested, for example by misaligning the bias to a different spot on the cell area and repeating the measurement. The second assumption might become untrue for highly efficient upconvertor materials, but in any case would lead to an underestimation of the UC performance. An alternative method for switching off the contribution of a liquid UC unit is to aerate the TTA-UC solution $^{24}$. This, on the other hand, leads to destruction of the dye molecules by singlet oxygen created upon illumination, changing the optical characteristics of the upconvertor.

We have generalized the above scheme, using standard photodetectors in place of solar cells, to measure raw upconversion efficiencies. ${ }^{110}$ While many of the researchers reporting upconversion efficiencies do so using relative actinometry, this method is inappropriate for use with the optically dense samples required for efficient operation under one-sun excitation. We have coupled broadband, white-light biasing with a modulated monochromatic probe to measure excitation spectra of upconvertors under solar-relevant conditions. The analysis is similar to that laid out below, and is detailed in Reference 110 .

3.4.2 Analysis scheme. Using the measurement scheme described above, a quantitative analysis of the UC-augmented QE curves becomes possible: ${ }^{93}$ The first quantity to be determined is the effective solar concentration seen by the upconvertor. The rate of excitation of an individual sensitizer molecule under 1 sun conditions $(1 \odot)$ is denoted $k_{\phi \odot}$, and is calculated by multiplication of the AM1.5G solar spectrum, $\rho_{\odot}$, in photons $\mathrm{cm}^{-2} \mathrm{~s}^{-1} \mathrm{~nm}^{-1}$ by the transmission of the solar cell, $T_{\mathrm{SC}}$, and integrating the product of this with the absorption cross section of the sensitizer species, $\sigma(\lambda)$ in $\mathrm{cm}^{2}$,

$$
k_{\phi \odot}=\int \rho_{\odot}(\lambda) T_{\mathrm{SC}}(\lambda) \sigma(\lambda) \mathrm{d} \lambda .
$$

As mentioned in Section 2.2, typical values for $k_{\phi \odot}$ are in the $2-10 \mathrm{~s}^{-1}$ range. The irradiation $I_{b}$ of the bias beam in photons 
per area per time is used to calculate the pump rate under the given experimental conditions, that is $k_{\phi b}=\sigma\left(\lambda_{b}\right) T_{\mathrm{SC}}\left(\lambda_{b}\right) I_{b}$ with the bias laser wavelength $\lambda_{b}$. The ratio $C=k_{\phi b} / k_{\phi} \odot$ then gives the effective solar concentration sensed by the upconvertor.

In the nonlinear regime (cf. Fig. 3), that is, under inefficient operating conditions of the upconvertor, and assuming efficient triplet energy transfer, the rate equations from Section 2.2 can be simplified to yield the steady-state emitter triplet concentration

$$
\left[{ }^{3} E^{*}\right](z)=\frac{k_{\phi}(z)\left[{ }^{1} S\right]}{k_{1}^{E}} .
$$

Here we introduced a spatial coordinate $z$ which denotes the depth inside the upconverting material, to account for the decay of the incident photon flux as the light penetrates the UC unit. Since the upconverted light production is proportional to the triplet concentration squared, one can write that the UC photon production rate is

$$
d \mathrm{Y}(z)=W_{T T A}(z) \cdot d V=\frac{k_{2}^{E E} \eta_{\operatorname{conv}} \Phi_{F}}{2} \frac{k_{\phi}(z)^{2}\left[{ }^{1} S\right]^{2}}{k_{1}^{E 2}} A \cdot d z .
$$

Under experimental conditions, $k_{\phi}$ has contributions from the bias beam and the monochromated probe beam. Denoting these additive contributions $k_{\phi b}$ and $k_{\phi p}$,

$$
d \mathrm{Y}(z) \propto\left[{ }^{1} S\right]^{2}\left(k_{\phi b}(0) e^{-\alpha_{b} z}+k_{\phi p}(0) e^{-\alpha_{p} z}\right)^{2} d z
$$

where the constants have been omitted, and the quantities $\alpha_{b}$ and $\alpha_{p}$ denote the absorption coefficients of the sensitizer species which are proportional to the molecular absorption cross sections at the bias and probe wavelengths, respectively,

$$
\begin{aligned}
& \alpha_{b}=\sigma_{b}\left[{ }^{1} S\right] \\
& \alpha_{p}=\sigma_{p}\left[{ }^{1} S\right] .
\end{aligned}
$$

Integration over $z$ gives

$$
\begin{aligned}
\mathrm{Y}=\int d \mathrm{Y}(z) & \propto\left[{ }^{1} S\right]^{2}\left(\frac{k_{\phi b}^{2}}{2 \alpha_{b}}+\frac{k_{\phi p}^{2}}{2 \alpha_{p}}+\frac{2 k_{\phi p} k_{\phi b}}{\alpha_{p}+\alpha_{b}}\right) \\
& \propto\left[{ }^{1} S\right]\left(\frac{I_{b}^{2} \sigma_{b}}{2}+\frac{I_{p}^{2} \sigma_{p}}{2}+\frac{2 I_{p} I_{b} \sigma_{p} \sigma_{b}}{\sigma_{p}+\sigma_{b}}\right)
\end{aligned}
$$

in case of well-behaved transmission of the solar cell which does not vary drastically around the active wavelength region of the UC unit.

Now, the linear response of the upconvertor with probe light is the quantity of interest which is determined in a QE measurement employing lock-in detection. The intensity of the probe impinging on the solar cell is larger than $I_{p}$ by a factor
$1 / T_{\mathrm{SC}}\left(\lambda_{p}\right)$, where $T_{\mathrm{SC}}\left(\lambda_{p}\right)$ is the solar cell transmission at the probed wavelength. Thus

$$
\frac{d \mathrm{Y}}{d I_{p}(\text { front })} \propto\left[{ }^{1} S\right] T_{\mathrm{SC}}\left(\lambda_{p}\right)\left(I_{p} \sigma_{p}+\frac{2 I_{b} \sigma_{p} \sigma_{b}}{\sigma_{p}+\sigma_{b}}\right) .
$$

Since the probe light is indeed small compared to the bias, the first term inside the parentheses can be ignored, and the augmentation of the QE curve is proportional to the second term. Denoting the $\mathrm{QE}$ in the absence of upconversion $\mathrm{QE}_{0}$, we obtain

$$
\begin{gathered}
\mathrm{QE}_{\mathrm{UC}}=\mathrm{QE}_{0}+\text { const. } \times \frac{T_{p} \sigma_{p} \sigma_{b}}{\sigma_{p}+\sigma_{b}} \\
\frac{\mathrm{QE}_{\mathrm{UC}}}{\mathrm{QE}_{0}}=1+\text { const. } \times \frac{T_{p}}{\mathrm{QE}_{0}} \frac{\sigma_{p} \sigma_{b}}{\sigma_{p}+\sigma_{b}} .
\end{gathered}
$$

This means that the experimentally observed QE ratio can be modelled using the absorption spectrum of the sensitizer molecules, and the transmission and baseline QE curves of the solar cell. Indeed we have found that this model describes the measured QE data of TTA-UC-enhanced solar cells of various types very well, as can be seen for the example of a P3HT:ICBA organic bulk heterojunction solar cell ${ }^{95}$ in Fig. 7.

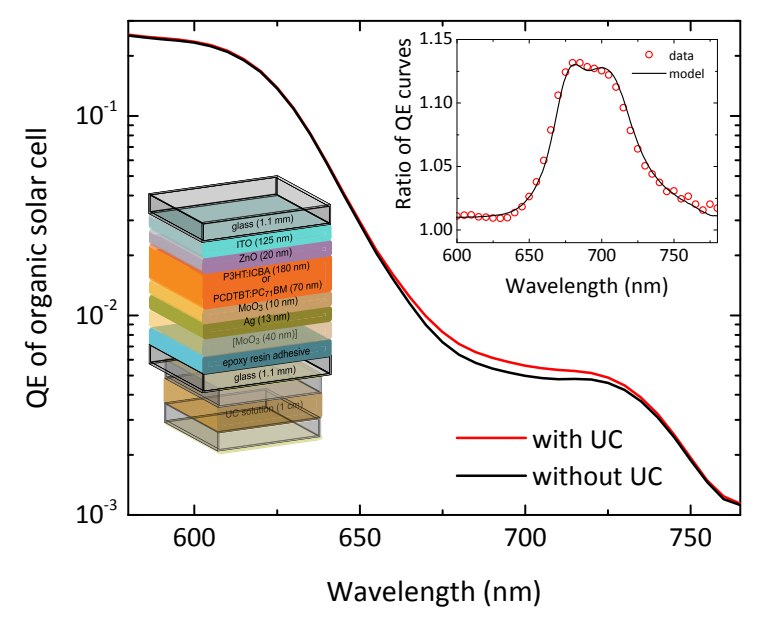

Fig. 7 TTA-UC enhancement signal for a P3HT:ICBA organic solar cell. The red quantum efficiency curve shows the situation with UC contribution and the black line is the baseline QE. The inset shows the ratio of the two curves, with a single-parameter fit of the model described in the text. The picture shows the device structure of the employed solar cell.

3.4.3 Figure of merit for UC-enhanced solar cells. To be able to compare the performance of UC-enhanced solar cells measured with a biased upconversion unit, we have to 
trace back the measured current enhancement to the situation corresponding to one-sun illumination. To this end we use the solar concentration factor as defined above to be $C=k_{\phi b} / k_{\phi \odot}$.

We calculate the current enhancement that results from the augmentation of the solar cell with the upconvertor at the effective number of suns imposed by the bias light, by the equation

$$
\Delta j_{\mathrm{SC}}=C e \int \Phi_{\mathrm{AM} 1.5 \mathrm{G}}(\lambda)\left(\mathrm{QE}_{\mathrm{UC}}(\lambda)-\mathrm{QE}_{0}(\lambda)\right) d \lambda,
$$

where $e$ is the elementary charge. From $\Delta j_{\mathrm{SC}}$, the upconversion figure of merit $\zeta$ is calculated as

$$
\zeta=\frac{\Delta j_{\mathrm{SC}}}{C^{2}}
$$

to take into account the effective solar concentration $C$ and the quadratic nature of the UC process at the illumination densities employed. The choice of this procedure is validated by the fact that for low solar concentration factors - typically below 5 suns - the figure of merit (FOM) is indeed found to be constant upon variation of the bias beam intensity. For higher solar concentration the system approaches the transition to the linear regime (cf. Fig. 3), which means that the obtained FOM value is penalized by the assumption of a quadratic behaviour due to the saturating UC quantum yield.

Table 2 shows our best experimental results for different types of thin-film solar cells augmented with TTAupconversion, as well as the best results for thin-film and crystalline wafer-based solar cells enhanced by lanthanoid-UC reported in the literature. In the following section we will briefly discuss the performance reached with each solar cell, and the pending issues in the optimization of the respective UC unit.

\subsection{Organic and dye-sensitized solar cells}

Both organic and dye-sensitized solar cells are ideal candidates for the combination with TTA-upconversion due to their comparably large absorption thresholds. The latest generation of organic bulk heterojunction solar cells can provide significant spectral response as far into the infrared as $800-900 \mathrm{~nm}$ based on low-bandgap polymers such as PCPDTBT and its derivatives, ${ }^{112}$ but for most standard blends such as P3HT:PCBM the QE does not extend beyond 650$700 \mathrm{~nm} .{ }^{113}$ There are already DSSCs with considerable spectral response down to roughly $900 \mathrm{~nm}$, mostly based on the black dye, ${ }^{114}$ but even some of the newest highly efficient DSSC architectures such as porphyrin-based co-sensitized DSSCs ${ }^{115,116}$ do not reach above the wavelength range of $750 \mathrm{~nm}$ in terms of spectral response. This means that for both classes of solar cells, the porphyrin-based TTA-sensitizers reported so-far ${ }^{35}$ suffice to extend the utilization of the solar spectrum for most present devices. In our recent publication we have combined two different organic bulk heterojunction cells with a semitransparent design with an external UC unit. ${ }^{95}$ We further adapted a DSSC to host the upconvertor inside the device. ${ }^{96}$

3.5.1 Organic solar cells. The combination of an organic solar cell with a TTA-upconvertor requires a bifacial architecture. Bifacial - or semitransparent, as is often used synonymously - organic solar cells are not trivially made as the standard layer sequence requires a low work function metal as back contact which cannot easily be replaced by a transparent electrode. Inverted device architectures have recently enabled the fabrication of semitransparent polymer-based solar cells, mostly with PEDOT:PSS transparent conductive polymer front contacts ${ }^{117,118}$ or a combination of metal oxides and a very thin semitransparent metal. ${ }^{119}$ In our study we employed semitransparent solar cells following the second approach, fabricated at Karlsruhe Institute of Technology (KIT).

Our cells had the layer sequence glass/ITO cathode/ZnO buffer/photoactive blend/ $\mathrm{MoO}_{3}$ interlayer/semi-transparent silver anode. The active blends employed in the two cell types were PCDTBT:PC ${ }_{71} \mathrm{BM}$, as well as P3HT:ICBA, with the latter cell type also incorporating a topmost $\mathrm{MoO}_{3}$ light coupling layer (cf. Fig. 7). The PCDTBT:PC 71 BM cells achieved notable power conversion efficiencies of up to $3.8 \%$ under illumination through the ITO cathode and $2.4 \%$ for illumination through the silver anode. The P3HT:ICBA solar cells exhibited efficiencies of up to $3.1 \%$ and $1.7 \%$, respectively. Further details on the fabrication can be found in Reference 95 . We employed the UC unit hosted in a standard cuvette, filled with $100 \mu \mathrm{m}$ diameter Ag-coated glass beads as discussed above in Section 3.3.2.

The upconversion FOMs reached with the polymer solar cells were between $0.24-1.60 \times 10^{-4} \mathrm{~mA} / \mathrm{cm}^{2}$ and thus the lowest among the range of thin-film solar cells studied so-far, and showed pronounced differences with respect to the orientation of the cell. Upon illumination of the cell through the ITO layer we measured FOMs that were 50\% lower than upon illumination through the Ag electrode. The apparent reason for this is the dependence of the solar cell QEs on orientation which stems from limited exciton diffusion lengths and the resulting sensitivity on the spatial positions of the electric field amplitude maxima, ${ }^{120}$ as well as from optical losses in the $\mathrm{Ag}$ electrode. In the usual operation scheme with illumination through the substrate glass and ITO cathode, the upconvertor is penalized by the absorptive $\mathrm{Ag}$ layer on the rear which is then positioned in between the active blend and the upconverting material. This leads to a lower FOM for this orientation. For illumination through the $\mathrm{Ag}$ anode on the other hand, the upconverted photons can be harvested by the cell with fewer optical losses, but with a significantly lower quantum effi- 
Table 2 Current enhancement and upconversion figure-of-merit for different upconversion-assisted solar cells.

\begin{tabular}{|c|c|c|c|c|c|c|c|}
\hline \multirow[t]{2}{*}{ Solar cell type } & \multicolumn{3}{|c|}{ Upconvertor } & \multirow{2}{*}{$\begin{array}{l}C \\
\odot\end{array}$} & \multirow{2}{*}{$\begin{array}{c}\Delta \mathrm{j}_{s c} \\
\mathrm{~mA} / \mathrm{cm}^{2}\end{array}$} & \multirow{2}{*}{$\begin{array}{c}\mathrm{FOM} \zeta \\
\mathrm{mA} / \mathrm{cm}^{2} / \bigodot^{2}\end{array}$} & \multirow[t]{2}{*}{ Ref. } \\
\hline & type & constituent $\mathrm{A}$ & constituent B & & & & \\
\hline 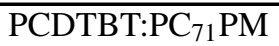 & TTA-UC & $1.3 \mathrm{mM}$ PQ4PdNA & $11 \mathrm{mM}$ rubrene & 28.9 & 0.129 & $0.15 \times 10^{-3}$ & 95 \\
\hline P3HT:ICBA & TTA-UC & $1.4 \mathrm{mM}$ PQ4PdNA & $35 \mathrm{mM}$ rubrene & 17.3 & 0.048 & $0.16 \times 10^{-3}$ & 95 \\
\hline DSSC & TTA-UC & $0.6 \mathrm{mM}$ PQ4PdNA & $33 \mathrm{mM}$ rubrene & 3.0 & $2.25 \times 10^{-3}$ & $0.25 \times 10^{-3}$ & 96 \\
\hline a-Si:H & TTA-UC & $0.9 \mathrm{mM}$ PQ4PdNA & $13 \mathrm{mM}$ rubrene & 19 & 0.275 & $0.76 \times 10^{-3}$ & 95 \\
\hline DSSC & TTA-UC & $0.8 \mathrm{mM}$ PQ4PdNA & hybrid emitter ${ }^{a}$ & 0.3 & $4.05 \times 10^{-4}$ & $4.50 \times 10^{-3}$ & 111 \\
\hline $\mathrm{a}-\mathrm{Si}: \mathrm{H}$ & TTA-UC & $0.8 \mathrm{mM}$ PQ4PdNA & hybrid emitter $^{a}$ & 1.4 & $4.70 \times 10^{-3}$ & $2.40 \times 10^{-3}$ & 111 \\
\hline$\overline{D S S C}$ & YAG:(Er,Yb) & $3 \% \mathrm{Yb}^{3+}$ & $0.5 \% \mathrm{Er}^{3+}$ & $?$ & 0.2 & $?$ & 87 \\
\hline $\mathrm{a}-\mathrm{Si}: \mathrm{H}$ & $\mathrm{Gd}_{2} \mathrm{O}_{2} \mathrm{~S}:(\mathrm{Er}, \mathrm{Yb})$ & $10 \% \mathrm{Yb}^{3+}$ & $5 \% \mathrm{Er}^{3+}$ & 20 & 0.1 & $0.25 \times 10^{-3}$ & 86 \\
\hline $\mathrm{c}-\mathrm{Si}$ & mono- $\mathrm{BaY}_{2} \mathrm{~F}_{8}$ : $\mathrm{Er}$ & $30 \% \mathrm{Er}^{3+}$ & - & 94 & 17.0 & $1.92 \times 10^{-3}$ & 83 \\
\hline
\end{tabular}

${ }^{a}$ mixture of rubrene and 9,10-bis-phenylethynylanthracene

ciency, leading to an improved FOM as compared to the other orientation, but still somewhat lower than for the other thinfilm solar cells. A next development step would be to combine the TTA-UC unit with an inverted OPV cell comprising a PEDOT:PSS top contact layer to avoid the mentioned parasitic optical losses. In case semitransparent OPV devices reach efficiencies in the range of a-Si:H devices in the future, they are to be expected to exhibit comparable UC-related photocurrent gains. For low-bandgap polymer absorbers ${ }^{112}$ it might be required to employ sensitizers absorbing further in the infrared, which are however available already now ${ }^{35}$.

3.5.2 Dye-sensitized solar cells. Classical dye-sensitized solar cells incorporate a redox couple such as the iodide/triiodide system in an organic solvent, in order to regenerate the dye after its photon-induced electron injection into the $\mathrm{TiO}_{2} .{ }^{114,121}$ More recent DSSC architectures mostly employ a $\mathrm{Co}(\mathrm{II} / \mathrm{III})$ tris(bipyridyl)-based redox electrolyte which allows higher photovoltages. ${ }^{116}$ Leaving aside the solid-electrolyte DSSC concepts employing conducting polymers, solid molecular hole conductors (such as spiro-MeOTAD) or inorganic hole conductors, ${ }^{122}$ this means that the electrolyte is a liquid solution which needs to be encapsulated between the dyecoated mesoporous $\mathrm{TiO}_{2}$ layer and the counter-electrode. As this procedure is an integral part of the processing sequence and leads to a device which is terminated by glass sheets on both sides, it is only a small additional task to include a second cavity to host the TTA unit.

In our study on UC-enhanced DSSCs we therefore pursued an integrated UC device, in which a solution-based UC system is contained within an encapsulated chamber on the back of the DSSC, similar to that which holds the active DSSC system (Fig. 8B). DSSCs were made at the University of Wollongong (UoW). This chamber included an $\mathrm{Al}_{2} \mathrm{O}_{3}$ back-reflector coated onto the glass back-sheet and was engineered to have a thickness of $120 \mu \mathrm{m}$ that allows optimal optical output from the TTA-UC solution in combination with the used concentra- tions, based on the considerations presented in Section 3.3.2. This architecture bears resemblance to tandem DSSC architectures. However, no extra TCO layer is required because the second cavity uses plain soda lime glass resulting in minimal additional cost. We chose D149 to be the active dye in our cell concept as its peak absorption (when adsorbed onto $\mathrm{TiO}_{2}$ ) matches the peak emission wavelength of rubrene (cf. Fig. 8A and Fig. 5).

Indeed, we found that the good match of the dye absorption and the direct incorporation of the UC unit minimizing optical losses leads to FOMs around $0.25 \times 10^{-3} \mathrm{~mA} / \mathrm{cm}^{2}-$ higher than for the organic solar cells but still inferior to a$\mathrm{Si}: \mathrm{H}$ cells (to be discussed in the next section). The integration strategy might be a practical method for incorporating TTA-UC into PV devices in general. However, the organic solvent hosting the TTA system poses a challenge to the encapsulation. We used Surlyn (Solaronix SA) hot melt adhesive to join the glass sheets when forming the cavities for the electrolyte and TTA system, which is not compatible with highly volatile solvents such as toluene. This points to the importance of finding alternative, less volatile host media for TTA-UC systems, such as ionic liquids. ${ }^{123}$ Using a hybrid-emitter TTA system we have recently obtained a FOM of $4.50 \times 10^{-3} \mathrm{~mA} / \mathrm{cm}^{2}$ with a DSSC using our classical backreflector design based on silver-coated glass beads. To our knowledge, this represents the highest enhancement figure-ofmerit for upconversion-enhanced solar cells (cf. Table 2). Details about the experiments and the novel hybrid TTA systems will be published elsewhere soon. ${ }^{111}$.

\subsection{Thin-film silicon solar cells}

Hydrogenated amorphous silicon (a-Si:H) solar cells are probably the most straightforward candidate for combination with a TTA-upconvertor as they provide reasonably high efficiencies of up to $10.1 \%$ but show an absorption threshold of 


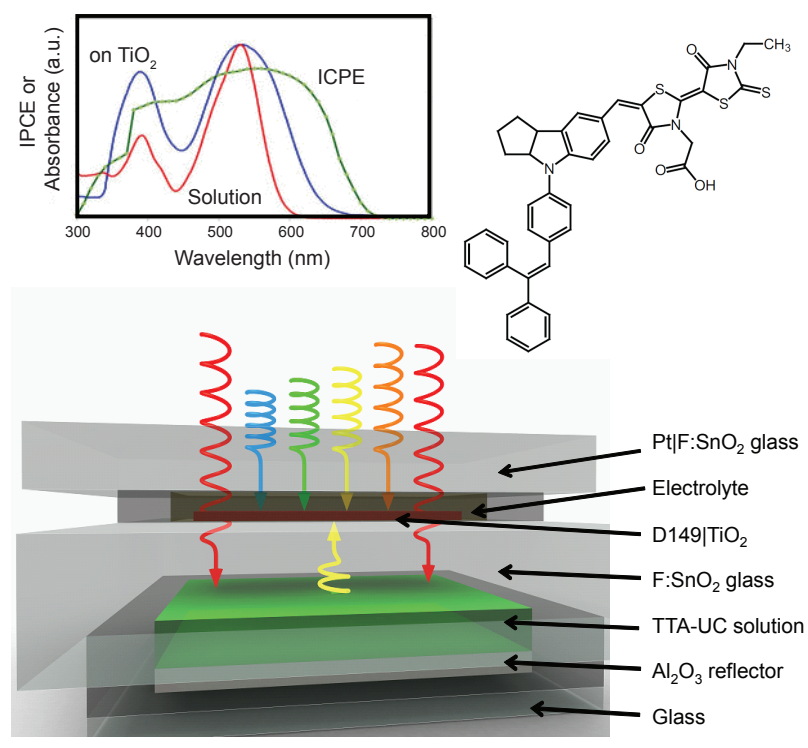

Fig. 8 (A) Absorption characteristics of the dye D149 employed in the upconversion-enhanced dye-sensitized solar cell ${ }^{96}$ (picture adapted from Mitsubishi Paper Mills Ltd.). Comparison with Fig. 5 shows the good overlap with the rubrene emission. (B) Device structure of the UC-enhanced DSSC with an integrated cavity to host the TTA-upconvertor.

roughly $700 \mathrm{~nm} .{ }^{124}$ At the same time it is fairly easy to implement a semitransparent design as a-Si:H absorbers withstand the deposition of a backside TCO layer. We therefore used a-Si:H solar cells as the workhorse during our optimization of the TTA materials and optics of the combined system. ${ }^{47,93,95,104}$

The cells we employed were a-Si:H $p-i-n$ solar cells with $i$-layer thicknesses of between $90-150 \mathrm{~nm}$. In the course of our studies we found that the UC performance is increased when the light trapping of the solar cell is reduced, as the near-threshold transmission is thereby increased. For this reason we omitted texturing of the front-side TCO which, at the same time, allowed us to increase the $i$-layer thickness while maintaining high sub-threshold transmittance. Our best bifacial a-Si:H $p-i-n$ cells employed a smooth $\mathrm{ZnO}: \mathrm{Al}$ front TCO layer, a p-doped $\mu \mathrm{c}$-Si $/ \mu \mathrm{c}-\mathrm{SiO}_{x} / \mathrm{a}-\mathrm{Si}: \mathrm{H}$ triple layer stack, ${ }^{125}$ a $150 \mathrm{~nm}$ thick (i)a-Si:H absorber, a $\mu \mathrm{c}-\mathrm{Si}$ backside n-doped layer and a $\mathrm{ZnO}: \mathrm{Al}$ back contact TCO layer. We employed industrial thin-film processing by plasma-enhanced chemical vapor deposition (PECVD) and reactive sputtering on $30 \times 30$ $\mathrm{cm}^{2}$ glass sheets at Helmholtz-Zentrum Berlin für Materialien und Energie (HZB). The substrates were cut into $10 \times 10 \mathrm{~cm}^{2}$ pieces afterwards, each containing $201 \times 1 \mathrm{~cm}^{2}$ individual solar cells. The overall conversion efficiency of the semitransparent a-Si:H cells was a notable $7.0 \%$ without any backside reflector.
During the measurements of UC-enhanced a-Si:H solar cells we connected the UC unit by different means: In a standard cuvette without back-scattering medium ${ }^{47}$ and filled with $100 \mu \mathrm{m}$ diameter Ag-coated glass beads, ${ }^{93,95}$ or using the half cuvette and different back-reflecting or -scattering media. ${ }^{104}$ The best results, including our record $2.40 \times 10^{-3} \mathrm{~mA} / \mathrm{cm}^{2}$ current increase (cf. Table 2) following the implementation of a hybrid-emitter TTA system ${ }^{20,111}$, were obtained with the cuvette filled with Ag-coated beads.

Figure 9 shows the history of the FOM obtained with the different classes of devices, as compared to the best result of a thin-film solar cell enhanced with lanthanoid upconversion. ${ }^{14}$ The dashed line represents the maximum current enhancement of our best a-Si:H solar cell that would be possible with our present flagship TTA system if it was operating at the maximum quantum yield that has been experimentally demonstrated for high illumination density. This number of roughly $0.4 \mathrm{~mA} / \mathrm{cm}^{2}$ is based on detailed optical modeling in combination with the rate equation description. In our opinion it also marks the region where commercial application might become feasible in case the UC unit can be made inexpensive and durable. Although we have realized a significant increase of the FOM by two orders of magnitude since our first results, there are another two orders of magnitude to be gained in order to fully exploit the potential of the TTA system. Section 4 will be devoted to sketching ways that might lead to bridging this gap. Before we open this discussion we briefly review concepts for TTA-enhanced solar energy storage in the next section.

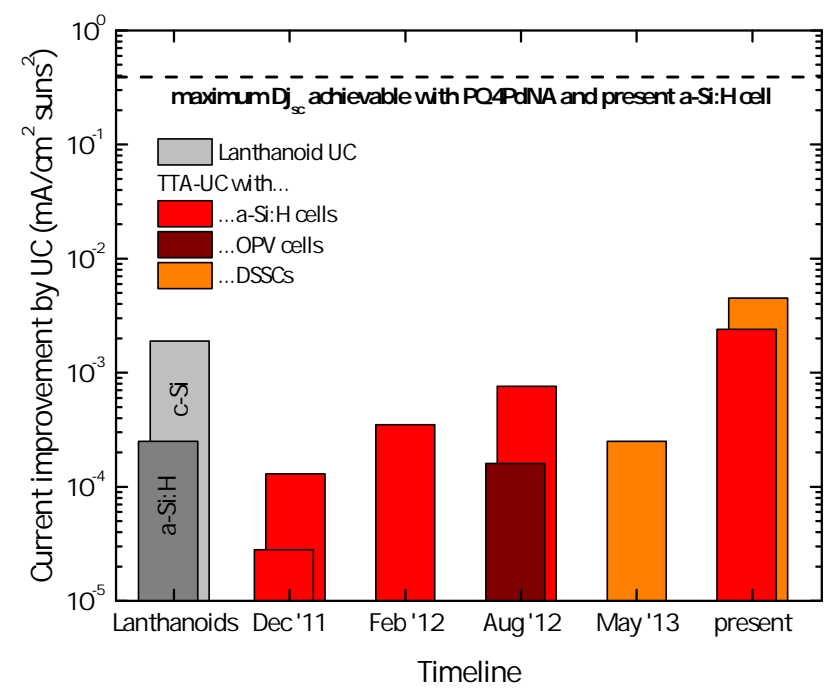

Fig. 9 History of the figure of merit for thin-film solar cells enhanced by TTA-upconversion as obtained by our group. ${ }^{47,93,95,96,111}$ For comparison, the best results for lanthanoid uconversion-enhanced silicon solar cells are shown in grey. ${ }^{83,86}$ 


\subsection{TTA-enhanced solar energy storage}

TTA upconversion hosts great potential for sensitizing photo(electro)chemical (PC/PEC) energy storage, as the respective materials and mechanisms usually have threshold energies well into the visible or even UV range of the spectrum. PEC-driven water splitting, for instance, requires a voltage of $1.23 \mathrm{~V}$ plus the over-potentials of the electrodes (thus, in practice, $2 \mathrm{~V}$ ), and respective devices are therefore restrained to high-bandgap absorber materials. One way of achieving the required high voltage is to invoke multijunction PV devices, which either efficiently utilise the spectrum but are highly expensive to manufacture such as III-V-based systems, ${ }^{126}$ or consist of thin-film multijunction cells incorporating high-bandgap absorber materials such as a-Si: $\mathrm{H}^{127}$ and again suffer from dominant sub-bandgap losses.

The domain of metal oxide PEC electrode materials faces similar issues: Respective materials have large bandgaps of $>2 \mathrm{eV}$, giving rise to very significant sub-bandgap losses, and even for the combination with a driver solar cell, the choices are again limited to high-voltage high-bandgap PV devices that leave a large part of the long-wavelength region of the spectrum unused. ${ }^{128}$

This means that harvesting and converting sub-bandgap photons by upconversion is highly relevant for PEC and PC devices, as inexpensive tandem PV devices which efficiently use the solar spectrum and deliver a high voltage are presently unavailable. TTA-UC is particularly interesting for this purpose as relevant energy ranges for harvesting and re-emission can lie well in the visible or even (in the case of high-gap metal oxide electrodes) in the UV region of the spectrum.

Until now, only few reports are documented in the literature where TTA-UC has been used to augment PEC/PC processes and devices. The majority of those concerns the sensitization of the oxygen evolution halfreaction of water splitting using a $\mathrm{WO}_{3}$ photoanode by green-to-blue TTA-upconversion based on a platinum(II)or palladium(II)-octaethylporphyrin/9,10-diphenylanthracene ([Pt/Pd]OEP/DPA) TTA couple. Khnayzer et al. employed the TTA materials in a liquid solution in toluene and encapsulated them in a glass cuvette, thus separating them from the aqueous phase, ${ }^{24}$ while Kim et al. used a hexadecane/polyisobutylene host which was enclosed in microcapsules made from ethoxylated trimethylolpropane triacylate ester (ETPTA) which allowed the introduction of the TTA system into the aqueous phase. ${ }^{129}$ While the first example employed truncated white light as the excitation source, the second and also the following used a $532 \mathrm{~nm}$ laser. Monguzzi et al. dispersed the TTA couple into an elastomeric poly-butylacrylate host, and immersed the resulting solid medium into water. ${ }^{55}$ These proofof-concept studies convincingly illustrate the potential of TTA in the field of PEC devices and highlight strategies that can render TTA-UC compatible with an aqueous environment. However, they rely on a photoanode which is not state-ofthe-art and employ a very crude optical design of the system, which leaves ample space for optimization of respective device concepts.

TTA-UC has also been employed to augment photochemical reactions that might be used for solar energy storage. Börjesson et al. used the aforementioned PdOEP/DPA system to sensitize a photoisomerization reaction of a fulvalene diruthenium derivative. Upon thermal or catalytic activation, the isomerism can be reversed and the compound releases the stored energy as heat, thus acting as a recyclable solar fuel. The liquid molecular solar thermal (MOST) storage medium and the liquid TTA system, both dissolved in toluene, were cycled through a microfluidic chip as the light-harvesting surface. ${ }^{23}$

TTA-UC was further employed to sensitize photochemical reactions for other applications: Islangulov et al. sensitized TTA between anthracene with the metal-to-ligand chargetransfer $(\mathrm{MLCT})$ sensitizer $\left[\mathrm{Ru}(\mathrm{dmb})_{3}\right]$ in order to produce reactive excited singlet species prone to cycloaddition chemistry, resulting in the formation of anthracene dimers. ${ }^{130} \mathrm{Jiang}$ et al. used a red-absorbing porphyrin/anthracene-derivative TTA couple to sensitize trans-cis-photoisomerization of azotolane in a cross-linked liquid-crystal polymer, resulting in a photomechanical effect with potential application in soft actuation. ${ }^{131}$

\section{Prospects for device applications}

We have seen, so far, that there is a clear application case for TTA-upconversion aiming to remedy sub-bandgap losses in thin-film solar cells and photo(electro)chemical devices. In recent years, a number of proof-of-concept application examples and - in some areas - a successive technological optimization have shown that TTA-UC can indeed be feasibly integrated into devices. The major bottleneck at present is the limited quantum yield under relevant operation conditions. In order to result in low-cost, large-scale deployable systems, the UCaugmented devices must not rely on geometric-optical concentration in order to function at appreciable yield. We therefore have to strive for

- incorporating concepts that enable the remarkably high quantum yields of present TTA-UC systems also under 1 -sun conditions,

- tackling the longevity of TTA systems under operation conditions, and

- developing facile and scalable concepts for oxygen defense and encapsulation. 


\subsection{Reported efficiencies under one-sun conditions}

While there are many reports of TTA-UC upconversion efficiencies, ${ }^{132}$ these are mostly obtained under strong pumping conditions using $\mathrm{cw}$ laser excitation. Under one-sun equivalent broadband excitation, MacQueen and Schmidt reported a red to yellow rubrene emitter system with a TTA quantum yield of $0.55 \%\left(\Phi_{T T A}=1.1 \%\right) .{ }^{110}$ Indeed, in that experiment upconversion excitation spectra were obtained with as low as 0.09 suns excitation. Monguzzi and co-workers recently reported a semiconductor nanocrystal-boosted system which exhibited a half-maximum output at 0.5 suns. ${ }^{108}$ The DPA emitter has a maximum upconversion yield of $25 \%$. Thus, the quantum yield at 0.5 suns is taken to be $12.5 \%$. For the same emitter, we obtain about $3 \%$ quantum yield $\left(\Phi_{T T A}=6 \%\right)$ under one sun excitation, increasing to $7 \%$ by three suns. Clearly, several percent quantum yields are possible under one-sun pumping. This must be increased several-fold. Below we outline several approaches one might take to bring about more efficient one-sun TTA-UC.

\subsection{How to further increase UC yield}

A possible guideline for this task is given in the form of Eq. 7, which is the steady-state solution of the rate equations. Here we see that in order to increase the steady-state concentration of emitter molecules in their triplet excited state $\left[{ }^{3} S^{*}\right]-$ and thus the UC yield - we have to increase the triplet lifetime $1 / k_{1}^{E}$, the sensitizer excitation rate $k_{\phi}$ as well as the concentration of sensitizers $\left[{ }^{1} S\right]$.

4.2.1 Increasing the triplet lifetime. The triplet lifetime of the emitter is governed by the rate of intersystem crossing. It is already orbitally forbidden, being a $\pi-\pi$ transition for PAHs, and if there are no heavy atoms to promote the crossing back to the ground state, it would at first appear that nothing can be done to decrease the rate. However, the rate depends on a matrix element involving a promoting vibrational mode, usually an out-of-plane bend for PAHs, and a Franck-Condon factor for the non-participating modes. The Franck-Condon factor for an iso-energetic transition is dominated by the contributions from the highest frequency modes, which in the case of PAHs are the $\mathrm{C}-\mathrm{H}$ stretches. This can be diminished by increasing the number of quanta that needs to be taken up by the modes, which is effected by increasing the mass and thus decreasing the frequency through deuteration. We have recently shown that upconversion yields can be increased by about $20 \%$ in this way for a model perylene emitter system. ${ }^{133}$ While this might seem a modest increase, it shows that phonon-engineering of emitter materials can affect upconversion efficiency. Deuteration itself is unlikely to be an economically viable strategy, with perdeuterated compounds costing some $100 \times$ more than their hydrogenated counterparts.

4.2.2 Increasing the excitation density. In order to increase the excitation rate of the sensitizers we can either increase the incident photon flux or the near-field environment of the sensitizer species. As mentioned before, global geometrical concentration is probably not a feasible way as the respective lens arrays and tracking systems drive the cost of the system. However, microfocussing arrays consisting of lenses or focussing reflectors may provide an elegant solution to this issue. We have recently shown that replacing a flat reflector behind the UC unit with a reflective surface bearing spherical indentations, that result in a focussing effect upon reflection of the light, leads to a $30 \%$ increase of the UC-related current increase of an a-Si:H solar cell ${ }^{104}$. The respective optical element was a hot-embossed aluminium-coated PTFE film, and was of mediocre optical performance. Optical modeling suggested that an optimized design (higher filling fraction and optimized depth of the indentations) could lead to a nine-fold increase of the UC yield. Thus, local geometrical concentration was highlighted to be a fairly easily implemented alternative to global concentrators, and may prove useful in augmenting the relatively dilute liquid TTA systems currently available. Note that the use of micro-optical focussing elements filled with the UC meterial renders the combined optical system insensitive to the incidence angle, which also spares the use of tracking systems, being usually required for macroscopic concentrators.

In case TTA materials with significantly higher dye concentrations become available (cf. the next section) and the characteristic absorption length approaches the wavelength of the light, near-field optical effects will become a very attractive route for increasing the sensitizer excitation rate. These might result from photonic structures such as distributed Bragg reflectors (DBR) or from plasmonic resonances hosted by metallic nanostructures.

DBRs have been employed to enhance lanthanoid-based upconversion ${ }^{134}$ by enhanced absorption of incident light via so-called slow light modes, and recent modeling work suggests beneficial effects also for TTA-upconversion. ${ }^{135}$ Plasmonic effects have been shown to enhance lanthanoid upconversion ${ }^{136}$ and were also employed in combination with TTAUC systems: Baluschev et al. used a conjugated polyfluorene polymer acting as TTA emitter, sensitized with PtOEP blended into the blue-emitting host, which was coated onto a silver surface employing a $15 \mathrm{~nm} \mathrm{LiF}$ spacer to prevent quenching of the triplets by the presence of the metal. Upon changing the orientation of the substrate with respect to an incident laser beam, the authors could clearly identify the TE and TM modes of the plasmonic resonance hosted by the Ag layer in the TTA yield. ${ }^{137}$ Recently, Poorkazem et al. dispersed plasmon- 
ically active silver nanoplates in a poly(methyl methacrylate) (PMMA) host which contained a PdOEP/DPA TTA-UC system, and observed a pronounced increase of the upconverted fluorescence signal as compared to a PdOEP/DPA/PMMA system lacking the silver nanoplates. ${ }^{138}$ Theoretical studies have further emphasized the possibility of enhancing TTA-UC in plasmonically active nanoparticles with crescent-shaped silver coatings. 139

In summary, it is without doubt that plasmonics can provide great potential for increasing the TTA-UC yield by nearfield enhancement of sensitizer transition rates, and possibly also by enhancing the outcoupling efficiency of the upconverted light. However, unlike for the geometrical concentration approach which has already proven to be useful, an insitu demonstration of the benefit of near-field optical effects in a solar energy conversion device is still lacking. Additionally, metal-induced exciton quenching might become an issue regarding plasmonic enhancement.

4.2.3 Increasing the molecular density. A third, equally important lever to higher UC yield is the concentration of the active species. Liquid systems are restrained to the $\mathrm{mM}$ range due to limited solubility of, primarily, the sensitizer species, while the solid-state approaches discussed in Section 2.3 mostly suffer from aggregation and phase separation when the dye load is increased. Thus far the most efficient TTA systems still reside in the liquid phase, and new architectures are required to increase dye load while preventing aggregation and proximity self-quenching. This review does not aim at providing the full scope of possible synthetic routes toward this goal. However we highlight some notable approaches which - in our view - might contribute to solving the pending issues in solid-state TTA.

An elegant and straightforward approach would be covalently linking sensitizer and emitter species. ${ }^{140}$ Recent studies imply that this indeed increases the UC yield in liquid solutions, ${ }^{141}$ while earlier studies have found an increase of the TTA photon yield of a porphyrin sensitizer end-capped poly-pentaphenylene solid TTA emitter ${ }^{142}$ as compared to a porphyrin-doped host. Although others have argued that the gain in UC efficiency in this system was minute and relate this finding to a possible exciton back-diffusion, ${ }^{58}$ these strategies point in the right direction but require much more effort in order to realize efficient and robust TTA systems tailored for solar energy applications.

Another interesting strategy is omitting the host matrix completely by functionalizing the active species with branched alkyl chains, thus creating a nonvolatile organic liquid solely consisting of the active species. Duan et al. pursued this approach functionalizing the PtOEP/DPA system and realized a concentration of up to $10 \mathrm{mM}$ of porphyrin sensitizer in the resulting DPA solution. ${ }^{143}$ The quantum yield was mea- sured to be up to $28 \%$.

Further, an increase of dye load should also be possible by tethering the active species onto nanoscopic support structures. Lissau et al. reported upconverted fluorescence from the PtOEP/DPA system adsorbed onto $\mathrm{ZrO}_{2}$ nanoparticles, but found their system to be limited by aggregation; sub-optimal dye loading and orientation; and oxygen quenching. An improved system featured functionalized DPA with carboxylate anchor groups on $\mathrm{ZrO}_{2}$ nanoparticles floating in a butyronitrile solution containing the PtOEP sensitizer, and showed improved performance ${ }^{144}$.

Our own activities in this field have been focussed around tethering the sensitizer species onto nanoscale scaffolds which are then immersed into a liquid emitter solution or interspersed with a polymeric emitter. First results of our red-absorbing porphyrins bound to silica nanoparticles in rubrene solution, in combination with amorphous silicon solar cells, showed a working system but no benefit with respect to the liquid system. ${ }^{94}$ Clearly, more work is required to shed light on the changes in dynamics, transfer and quenching rates associated with immobilized dyes in order to assess if this concept bears potential for improving TTA-UC efficiency.

Finally, an interesting strategy is to move away from the TTA couple paradigm and to introduce a third (or even more) active species. Successful attempts to combine two or more porphyrin sensitizers providing triplets to the same emitter were presented above and mainly aim at extending the spectral harvest of the TTA system. ${ }^{102,103}$ However, in contrast, employing more than one emitter species appears to yield a benefit in UC efficiency. First of all, the solubility problem can be mitigated if the sensitizer triplets are accepted by two separate species instead of one. In addition, there seems to be a synergetic effect in the combination of two emitting species which results in a clear gain in UC yield as compared to a classical TTA couple. ${ }^{20,145}$ Consequently, our newest and best solar cell results (cf. Table 2) were obtained with dual-emitter TTA systems. The exact reason for this effect is currently under investigation, and a respective analysis of our results will be published elsewhere soon.

\subsection{Longevity}

For applications in solar energy harvesting, an encapsulated TTA-UC system would be required to last for several years. Even if one might consider a liquid TTA system in a flow reactor where an exchange of the active solution is more easily achieved ${ }^{23}$, the economic feasibility of applying a TTAUC booster to a solar energy device crucially depends on the longevity. However, to our knowledge, no experimental results have been reported so-far regarding photodegradation of TTA systems under application-relevant conditions. To this end, we have collected preliminary data which we present here 

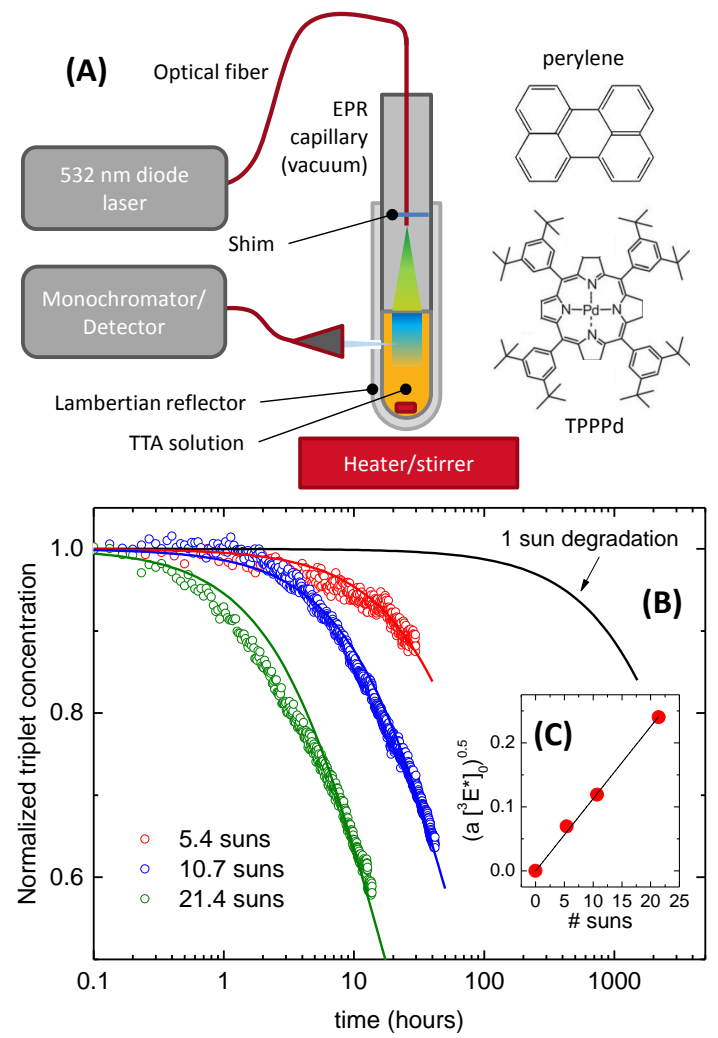

Fig. 10 Photo-degradation of a TTA-UC system. (A) Setup for measuring the decay of UC yield over an extended period of time. (B) Analysis of the photo-degradation data based on model-based fitting. Details of the analysis are given in the text. (C) The time constant $a\left[{ }^{3} E^{*}\right]_{0}$ of the model fit shows a quadratic dependence on the incident excitation power density. Extrapolation to 1 sun conditions yields the black curve in panel (B).

for the first time.

The experimental setup consisted of a TPPPd/perylene TTA couple, ${ }^{37}$ dissolved in a highly nonvolatile synthetic silicone oil. We inserted a well-defined amount of this mixture into an EPR tube with $5 \mathrm{~mm}$ inner diameter, including a miniature magnetic stirrer. The outside of the tube was covered with a white Lambertian reflector, leaving only a roughly $1 \mathrm{~mm}$ sized hole for detection of the upconverted fluorescence through an optical fiber using a monochromator/CCD camera assembly (Princeton Instruments). A $532 \mathrm{~nm}$ diode laser coupled into an optical fiber was inserted into the EPR tube such that the light spot covered the entire surface of the TTA solution (Fig. 10A). The EPR tube was evacuated to the $10^{-5}$ mbar range using a diffusion pump and the pump line was connected during the entire duration of the experiment. After pumping on the solution for $2 \mathrm{~h}$ during stirring to deaerate and evaporate residual volatile components, the experiment was started by exposing the solution to the $532 \mathrm{~nm}$ light. Over the course of several hours, fluorescence spectra were taken every minute and the peak height of the perylene fluorescence around $455 \mathrm{~nm}$ was monitored. After the experiment, the effective solar concentration was again calculated to be $C=k_{\phi b} / k_{\phi \odot}$, with $k_{\phi b}$ in this case assumed to be the total incident photon flux divided by the number of molecules in the cuvette, that is, assuming an optically hermetic system and a quasi-homogeneous flooding of the solution with incident light.

The obtained decay traces of the fluorescence intensity were afterwards analyzed with the help of a model. We normalized the square root of the fluorescence intensity which results in data sets of the relative decay of the steady-state emitter triplet density $\left[{ }^{3} E^{*}\right]_{t} /\left[{ }^{3} E^{*}\right]_{0} \cdot{ }^{27}$ We found that these curves could be reasonably fit assuming that the emitter species are destroyed by a second-order process,

$$
\frac{d\left[{ }^{3} E^{*}\right]_{t}}{d t}=-a\left[{ }^{3} E^{*}\right]_{t}^{2} \Rightarrow \frac{\left[{ }^{3} E^{*}\right]_{t}}{\left[{ }^{3} E^{*}\right]_{0}}=\frac{1}{a\left[{ }^{3} E^{*}\right]_{0} t+1} .
$$

The fit results are shown in Fig. 10B.

We noted from UV-VIS absorption spectra taken after the degradation run that $[\mathrm{E}]$ and $[\mathrm{S}]$ had been diminished equally such that the ratio $[\mathrm{S}] /[\mathrm{E}]$ was approximately constant. Thus, the photo-destruction mechanism must affect both molecular species.

We fit the decay curves for different effective light concentrations and found the square root of the time constant $\sqrt{a\left[{ }^{3} E^{*}\right]_{0}}$ to vary linearly with the incident laser power (Fig. 10C). Extrapolating the respective linear fit to 1 sun conditions we arrive at the black model curve in panel (B), predicting that after $1000 \mathrm{~h}$ at 1 sun conditions - corresponding to one year of outdoor operation in central Europe - the triplet concentration would have dropped by $10 \%$. After three years $30 \%$ loss would have occurred, corresponding to a loss in the UC photon yield of about $50 \%$.

While this analysis is only a first and crude step towards assessing the longevity of TTA systems under relevant conditions, we consider the results to be promising, even though the lifetime is most likely not yet sufficient for an economically feasible operation. Given the fact that the employed excitation energies $(h v)$ are $25 \%$ higher than for the red-absorbing TTA systems relevant to PV devices, and the energy accessible by second order processes might be up to $1 \mathrm{eV}$ lower in those TTA couples, the destruction rate will likely be reduced. The fact that the PV device protects the upconvertor from highenergy photons will further help to extend the lifetime of the TTA system. However, further and more detailed studies are needed to conclude about the longevity in device-relevant configurations, and dedicated materials design will be required in order to increase the lifetime under 1 sun conditions towards the order of 10 years or more. 


\subsection{Encapsulation and oxygen defense}

Oxygen is detrimental to the operation of TTA-UC as it scavenges triplet excitons from the active TTA species. The electronic ground-state of molecular oxygen has a triplet configuration of electron spins with a $T_{0}-S_{1}$ energy gap of $0.97 \mathrm{eV}$. This makes it an effective quencher of triplet-excited chromophores in TTA-UC systems by the reaction $\left[{ }^{3} \mathrm{O}_{2}\right]+\left[{ }^{3} \mathrm{M}^{*}\right]$ $\rightarrow\left[{ }^{1} \mathrm{O}_{2}^{*}\right]+\left[{ }^{1} \mathrm{M}\right]$. Sustainably excluding oxygen is therefore a prime directive in the design of device-appended TTA-UC systems. Additionally, replacing highly volatile solvents such as toluene, which are commonly used for lab-based TTA systems, becomes mandatory for long-term encapsulation of TTA systems. While the containment of the TTA system in a closed glass cuvette after freeze-pump-thaw cycles is a practical method in the lab, device application requires new routes for both oxygen defense and encapsulation. In the literature we already find documents of very different approaches that might be viable to this end, and partly include rendering the TTA-system to be bio- or aqueous-compatible.

Polymeric micro- or nano-capsules filled with a liquid TTA system have been presented in a number of studies and allow stable operation in water, ${ }^{129,146-149}$ as do polymeric nanofibers containing nano-capsules filled with a liquid TTA system. ${ }^{150}$ Self-organized micellar carriers based on non-ionic surfactants have been presented and likewise allow transference of the system into water. ${ }^{151}$ There are also several alternatives to the highly volatile solvents: Ionic liquids have been presented as a completely nonvolatile host matrix, ${ }^{123}$ while hexadecane/polyisobutylene was found to be a less volatile host, also providing some degree of oxygen protection. ${ }^{129} \mathrm{Fi}-$ nally, matrices which have oxygen-scavenging properties can further reduce the detrimental impact of atmospheric conditions. ${ }^{152,153}$

In summary it appears that several complementary strategies for oxygen exclusion and encapsulation are already available. As for the longevity issue discussed above, focussed efforts are needed to explore the feasibility of those approaches in a device context.

\subsection{Materials Cost}

In the end, the uptake of photovoltaics is a trade-off between cost and efficiency, there being a market for cheap but reasonably efficient cells $(\eta \approx 10 \%)$, and a market for highly efficient yet expensive cells $(\eta>20 \%)$. The addition of an upconvertor to a thin-film solar cell must not add a considerable cost to its manufacture. The cost will comprise two components, the materials cost and the manufacturing cost. We begin with estimating the materials cost.

In order to absorb the sub-bandgap light, the sensitizer materials must be in a high enough concentration such that their absorption cross sections, $\sigma$, could be used to tesselate the rear of the solar cell. At a surface coverage of $1 / \sigma, 1 / e$ of the incoming radiation would be absorbed at peak, which, in conjunction with a back-reflector, has been determined to be optimal. ${ }^{93}$

The $\mathrm{PQ}_{4} \mathrm{Pd}$ porphyrin has a peak absorption cross section of $4 \AA^{2}$, which would yield an optimal surface concentration of $2.5 \times 10^{19} \mathrm{~m}^{-2}$, or $4 \times 10^{-5} \mathrm{~mol} \mathrm{~m}^{-2}$. With a molecular mass of $\sim 1500 \mathrm{amu}$, this translates to about $65 \mathrm{mg} \mathrm{m}^{-2}$. Now, while specialty research chemicals cost on the order of $\$ 1000 / \mathrm{g}$, vat dyes which are manufactured in bulk can be purchased for prices ranging from $\$ 1$ to $\$ 50 / \mathrm{kg}$. At $\$ 50 / \mathrm{kg}$, the dye cost would be just a third of a cent per square metre. The emitters in widespread use are already manufactured in bulk: Rubrene can be obtained for as little as $\$ 10 / \mathrm{kg}$, as can various perylene dyes, some of which are used in paints for vehicles. Phthalocyanines, which have been demonstrated as sensitizers, ${ }^{154}$ are available for as little as $\$ 1 / \mathrm{kg}$. Thus, given a choice of sensitizer and emitter species which are already in widespread use and having scalable synthesis, the cost for dye production could be well in the $\mathrm{c} / \mathrm{m}^{2}$ range.

In terms of elemental raw materials use, the palladium or platinum metal currently incorporated in the porphyrin sensitizers is expected to dominate the price. The cost of palladium is $\$ 780 / \mathrm{oz}$ at the time of writing. Assuming an absorption cross section of $4 \AA^{2}$, this amounts to $4 \mathrm{mg} \mathrm{m}^{-2}$, which would cost about $12 \mathrm{c} \mathrm{m}^{-2}$. Thus, the use of precious metals in the sensitizer species would be the main price driver given bulk synthesis prices as discussed above.

To pay for itself, the upconvertor must generate an additional $\mathrm{W}_{p} \$^{-1}$. Assuming a cell voltage of $0.5 \mathrm{~V}$ at its maximum power point, an additional $2 \mathrm{~A} \$^{-1}$ is required. At an upconvertor cost of $1 \$ \mathrm{~m}^{-2}$ - much higher than the more optimistic estimates outlined above - this amounts to $0.2 \mathrm{~mA} \mathrm{~cm}^{-2}$, which is at the upper end of what we believe is eventually achievable with a single sensitizer species. ${ }^{95}$ Note however that by broadening the absorption range through the use of multiple sensitizer species feeding the same emitter ${ }^{35}$, the current harvest could be increased by adding a single molecular species, thus leveraging the cost of the entire UC system.

Clearly, there is a need to identify upconversion materials which are either already in widespread use, have scalable syntheses, and forgo the use of precious metals. With respect to upconversion without heavy metals, BODIPY dyes were shouwn to function as rare-metal-free triplet sensitizers. ${ }^{30}$ It has further been demonstrated that zinc porphyrins can sensitize TTA-UC systems. ${ }^{155,156}$ Zinc costs on the order $\$ 2 / \mathrm{kg}$, which is a tiny fraction of the cost of palladium. While zinc compounds do not usually have the $\sim 100 \%$ triplet yields of palladium and platinum compounds, they are still high ( $\sim 80-90 \%)$, and since intersystem crossing is not presently a bottleneck in TTA-UC efficiency the prospects for achieving 
photochemical upconversion with cheap materials are good.

Regarding the manufactoring cost for integration of an UC unit into a solar energy harvesting device, a sincere estimate is hard to make based on the currently available UC systems. Clearly, the realization of an efficient solid-state TTAUC material would greatly improve the application perspective. However, incorporation of liquid materials does not generally preclude a large-scale application as can be seen from the example of liquid crystal flat panel displays. As a result, respective sealing and encapsulation methods are available, but a commercially viable application of liquid-based TTAUC might ultimately be hindered by the requirement of a second glass sheet to form the cavity hosting the UC unit. Thus, the application perspective of TTA-UC will crucially depend on further materials development, mainly tackling the challenges of solid state matrices as well as photo-degratation.

\section{Conclusion}

In conclusion, we have shown the status and prospects of device application for triplet-triplet annihilation upconversion in the context of solar energy conversion and storage. The application perspective of TTA-UC for thin-film PV and photo(electro)chemical storage is clearly given, due to the inherently large bandgaps of respective absorbers and ensuing transmission losses. It is apparent that the quantum yield of TTA-upconversion systems under device operation conditions is the crucial quantity to be optimized in the near future. Although it approaches the physical limit under high excitation flux for some TTA systems, it is mostly in the low percent range under 1-sun conditions. The combination of micro- or nano-optical enhancement schemes with tailored engineering of TTA materials to facilitate higher concentrations of the active species might pave the way to higher QEs in device configuration. Alongside this challenge in material and optical design, the longevity of the UC unit needs to be addressed within a technological effort. There seems to be a plethora of possible complementary approaches to oxygen defense and encapsulation, making it realistic that this aspect will not hinder application. Photo-degradation of the organic species is more likely to be a crucial issue, but very preliminary results let us hope that it can be resolved. Finally, we believe that TTA-UC has a bright future for solar energy harvesting if we are able to rise to the challenges set out above.

\section{Acknowledgment}

Much of the work summarized in this review was the result of sustained efforts by Y. Y. Cheng, R. W. MacQueen, A. N. Danos, M. J. Y. Tayebjee, B. Fückel, and R. G. C. R. Clady on TTA-UC characterization; and T. Khoury and M. J. Crossley on the synthesis of porphyrin sensitizers. We acknowledge K. Lips for initiating the German-Australian collaboration leading to many of the results presented herein. B. Stannowski, T. Hänel and S. Kirner from HZB are acknowledged for a-Si:H solar cell processing and characterization. We thank A. Colsmann, J. Czolk and U. Lemmer at KIT for OPV cell design and manufacturing. A. Nattestad, F. W. Thompson, A. J. Mozer and G. G. Wallace from UoW are acknowledged for the development and processing of the DSSCs. N. J. Ekins-Daukes is thanked for initiating our work on TTA-UC.

TFS acknowledges the Alexander von HumboldtFoundation for a Feodor Lynen fellowship. TWS acknowledges the Australian Research Council for a Future Fellowship.

The research projects generating the results summarized herein from our laboratory were funded by the Australian Renewable Energy Agency (Project A-023), with contributions from The New South Wales Government and The University of Sydney. Aspects of the research were supported under Australian Research Council's Discovery Projects funding scheme (DP110103300).

\section{References}

1 W. Shockley and H. J. Queisser, J. Appl. Phys., 1961, 32, 510-519.

2 M. C. Hanna and A. J. Nozik, J. Appl. Phys., 2006, 100, 074510.

3 M. J. Y. Tayebjee, A. A. Gray-Weale and T. W. Schmidt, J. Phys. Chem. Lett., 2012, 3, 2749-2754.

4 T. Hisatomi, J. Kubota and K. Domen, Chem. Soc. Rev., 2014.

5 M. Grätzel, Nature, 2001, 414, 338-344.

6 T. Schmidt and M. Tayebjee, in Comprehensive Renewable Energy, ed. A. Sayigh, Elsevier, Oxford, 2012, pp. $533-548$.

7 L. C. Hirst and N. J. Ekins-Daukes, Prog. Photovolt: Res. Appl., 2011, 19, 286-293.

8 M. A. Green, Third Generation Photovoltaics: Advances Solar Energy Conversion, Springer-Verlag, Heidelberg, 2003.

9 T. Trupke, M. A. Green and P. Würfel, J. Appl. Phys., 2002, 92, 41174122.

10 J. de Wild, A. Meijerink, J. K. Rath, W. G. J. H. M. van Sark and R. E. I. Schropp, Energy Environ. Sci., 2011, 4, 4835-4848.

11 F. Auzel, Chem. Rev., 2004, 104, 139-173.

12 B. M. van der Ende, L. Aarts and A. Meijerink, Phys. Chem. Chem. Phys., 2009, 11, 11081-11095.

13 A. Shalav, B. S. Richards, T. Trupke, K. W. Krämer and H. U. Güdel, Appl. Phys. Lett., 2005, 86, 013505.

14 S. Fischer, B. Fröhlich, H. Steinkemper, K. Krämer and J. Goldschmidt, Sol. Energ. Mat. Sol. C., 2014, 122, 197 - 207.

15 S. Baluschev, T. Miteva, V. Yakutkin, G. Nelles, A. Yasuda and G. Wegner, Phys. Rev. Lett., 2006, 97, 143903.

16 T. N. Singh-Rachford and F. N. Castellano, Coordin. Chem. Rev., 2010, 254, 2560-2573.

17 J. Z. Zhao, S. M. Ji and H. M. Guo, RSC Adv., 2011, 1, 937-950.

18 C. A. Parker and C. G. Hatchard, Proc. Chem. Soc., 1962, 386-387.

19 C. A. Parker, Proc. Roy. Soc. A, 1963, 276, 125-135.

20 X. Cao, B. Hu and P. Zhang, J. Phys. Chem. Lett., 2013, 4, 2334-2338. 
21 S. K. W. MacDougall, A. Ivaturi, J. Marques-Hueso, K. W. Krämer and B. S. Richards, Opt. Express, 2012, 20, A879-A887.

22 R. Martn-Rodríguez, S. Fischer, A. Ivaturi, B. Froehlich, K. W. Krämer, J. C. Goldschmidt, B. S. Richards and A. Meijerink, Chemistry of Materials, 2013, 25, 1912-1921.

23 K. Börjesson, D. Dzebo, B. Albinsson and K. Moth-Poulsen, J. Mater. Chem. A, 2013, 1, 8521-8524.

24 R. S. Khnayzer, J. Blumhoff, J. A. Harrington, A. Haefele, F. Deng and F. N. Castellano, Chem. Commun., 2012, 48, 209-211.

25 S. Baluschev, V. Yakutkin, T. Miteva, Y. Avlasevich, S. Chernov, S. Aleshchenkov, G. Nelles, A. Cheprakov, A. Yasuda, K. Müllen et al., Angew. Chem. Int. Ed., 2007, 46, 7693-7696.

26 S. Baluschev, V. Yakutkin, T. Miteva, G. Wegner, T. Roberts, G. Nelles, A. Yasuda, S. Chernov, S. Aleshchenkov and A. Cheprakov, New J. Phys., 2008, 10, 013007.

27 Y. Cheng, B. Fückel, T. Khoury, R. G. C. R. Clady, M. J. Y. Tayebjee, N. J. Ekins-Daukes, M. J. Crossley and T. W. Schmidt, J. Phys. Chem. Lett., 2010, 1, 1795-1799.

28 W. Zhao and F. N. Castellano, J. Phys. Chem. A, 2006, 110, 1144011445 .

29 R. R. Islangulov, D. V. Kozlov and F. N. Castellano, Chem. Commun., 2005, 3776-3778

30 C. Zhang, J. Zhao, S. Wu, Z. Wang, W. Wu, J. Ma, S. Guo and L. Huang, J. Am. Chem. Soc., 2013, 135, 10566-10578.

31 J. Sun, F. Zhong, X. Yi and J. Zhao, Inorg. Chem., 2013, 52, 6299-6310.

32 V. Jankus, E. W. Snedden, D. W. Bright, V. L. Whittle, J. A. G. Williams and A. Monkman, Adv. Funct. Mater., 2013, 23, 384-393.

33 T. N. Singh-Rachford and F. N. Castellano, J. Phys. Chem. A, 2009, 113, 5912.

34 B. Fückel, D. A. Roberts, Y. Cheng, R. G. C. R. Clady, R. B. Piper, N. J. Ekins-Daukes, M. J. Crossley and T. W. Schmidt, J. Phys. Chem. Lett., 2011, 2, 966-971.

35 V. Yakutkin, S. Aleshchenkov, S. Chernov, T. Miteva, G. Nelles, A. Cheprakov and S. Baluschev, Chem. - Eur. J., 2008, 14, 9846-9850.

36 T. N. Singh-Rachford, A. Haefele, R. Ziessel and F. N. Castellano, J. Am. Chem. Soc., 2008, 130, 16164.

37 Y. Y. Cheng, B. Fückel, T. Khoury, R. G. C. R. Clady, N. J. EkinsDaukes, M. J. Crossley and T. W. Schmidt, J. Phys. Chem. A, 2011, 115, 1047-1053.

38 T. N. Singh-Rachford and F. N. Castellano, Inorg. Chem., 2009, 48, 2541-2548.

39 J. E. Auckett, Y. Cheng, T. Khoury, R. G. C. R. Clady, N. J. EkinsDaukes, M. J. Crossley and T. W. Schmidt, J. Phys. Conf. Ser, 2009, 185, 012002

40 A. Monguzzi, J. Mezyk, F. Scotognella, R. Tubino and F. Meinardi, Phys. Rev. B, 2008, 78, 5.

41 A. Haefele, J. Blumhoff, R. S. Khnayzer and F. N. Castellano, J. Phys. Chem. Lett., 2012, 3, 299-303.

42 R. B. Piper, M. Yoshida, D. J. Farrell, T. Khoury, M. J. Crossley, T. W. Schmidt, S. A. Haque and N. Ekins-Daukes, RSC Adv., 2014, 4, 80598063.

43 T. N. Singh-Rachford, A. Nayak, M. L. Muro-Small, S. Goeb, M. J. Therien and F. N. Castellano, J. Am. Chem. Soc., 2010, 132, 1420314211.

44 D. Y. Kondakov, T. D. Pawlik, T. K. Hatwar and J. P. Spindler, J. Appl. Phys., 2009, 106, year.

45 Y. Cheng, T. Khoury, R. G. C. R. Clady, M. J. Y. Tayebjee, N. J. EkinsDaukes, M. J. Crossley and T. W. Schmidt, Phys. Chem. Chem. Phys., 2010, 12, 66-71.

46 B. Dick and B. Nickel, Chem. Phys., 1983, 78, 1-16.

47 Y. Y. Cheng, B. Fückel, R. W. MacQueen, T. Khoury, R. G. C. R. Clady, T. F. Schulze, N. J. Ekins-Daukes, M. J. Crossley, B. Stannowski, K. Lips and T. W. Schmidt, Energy Environ. Sci., 2012, 5, 6953-6959.
48 G. E. Arnaoutakis, J. Marques-Hueso, A. Ivaturi, K. W. Krämer, S. Fischer, J. C. Goldschmidt and B. S. Richards, Opt. Express, 2014, 22, A452-A464.

49 R. R. Islangulov, J. Lott, C. Weder and F. N. Castellano, J. Am. Chem. Soc., 2007, 129, 12652-12653.

50 A. Monguzzi, R. Tubino and F. Meinardi, J. Phys. Chem. A, 2009, 113, 1171-1174.

51 T. Miteva, V. Yakutkin, G. Nelles and S. Baluschev, New J. Phys., 2008, 10, 103002

52 T. N. Singh-Rachford, J. Lott, C. Weder and F. N. Castellano, J. Am. Chem. Soc., 2009, 131, 12007-12014.

53 J.-H. Kim, F. Deng, F. N. Castellano and J.-H. Kim, Chem. Mater, 2012, 24, 2250-2252.

54 T. N. Singh-Rachford and F. N. Castellano, J. Phys. Chem. Lett., 2009, 1, 195-200.

55 A. Monguzzi, F. Bianchi, A. Bianchi, M. Mauri, R. Simonutti, R. Ruffo, R. Tubino and F. Meinardi, Adv. Energ. Mater, 2013, 3, 680-686.

56 A. Monguzzi, M. Frigoli, C. Larpent, R. Tubino and F. Meinardi, $A d v$. Funct. Mater., 2012, 22, 139.

57 Y. C. Simon, S. Bai, M. K. Sing, H. Dietsch, M. Achermann and C. Weder, Macromol. Rapid Comm., 2012, 33, 498-502.

58 Y. C. Simon and C. Weder, J. Mater. Chem., 2012, 22, 20817.

59 P. E. Keivanidis, S. Baluschev, T. Miteva, G. Nelles, U. Scherf, A. Yasuda and G. Wegner, Adv. Mater., 2003, 15, 2095-2098.

60 S. Baluschev, P. Keivanidis, G. Wegner, J. Jacob, A. Grimsdale, K. Müllen, T. Miteva, A. Yasuda and G. Nelles, Appl. Phys. Lett., 2005, 86, 061904.

61 S. Bedair, M. Lamorte and J. Hauser, Appl. Phys. Lett., 1979, 34, 38-39.

62 N. H. Karam, R. R. King, M. Haddad, J. H. Ermer, H. Yoon, H. L. Cotal, R. Sudharsanan, J. W. Eldredge, K. Edmondson, D. E. Joslin et al., Sol. Energ. Mat. Sol. C., 2001, 66, 453-466.

63 http://www.ise.fraunhofer.de/de/presse-undmedien/presseinformationen/presseinformationen-2013/weltrekordsolarzelle-mit-44-7-prozent-wirkungsgrad, 2013.

64 A. Shah, P. Torres, R. Tscharner, N. Wyrsch and H. Keppner, Science, 1999, 285, 692-698.

65 Thin-film Silicon Solar Cells, ed. A. Shah, EPFL Press, Lausanne, Switzerland, 2010.

66 M. Wolf, Proc. IRE, 1960, 48, 1246.

67 G. Güttler and H. Queisser, Energ. Convers., 1970, 10, 51-55.

68 P. Würfel, Sol. Energ. Mat. Sol. C., 1993, 29, 403-413.

69 A. Luque and A. Martí, Phys. Rev. Lett., 1997, 78, 5014.

70 M. Keevers and M. Green, J. Appl. Phys., 1994, 75, 4022-4031.

71 L. Sang, M. Liao, Q. Liang, M. Takeguchi, B. Dierre, B. Shen, T. Sekiguchi, Y. Koide and M. Sumiya, Adv. Mater., 2014, 26, 1414 1420 .

72 N. López, L. Reichertz, K. Yu, K. Campman and W. Walukiewicz, Phys. Rev. Lett., 2011, 106, 028701.

73 F. Auzel, C. R. Acad. Sci., 1966, 263, 819.

74 N. Menyuk, K. Dwight and J. Pierce, Appl. Phys. Lett., 1972, 21, 159 161.

75 M. Haase and H. Schäfer, Angew. Chem. Int. Ed., 2011, 50, 5808.

76 P. Gibart, J.-C. Guillaume, K. Zahraman et al., Jpn. J. Appl. Phys., 1996, 35, 4401 .

77 A. Shalav, B. S. Richards and M. A. Green, Sol. Energ. Mat. Sol. C., 2007, 91, 829-842.

78 J. C. Goldschmidt, S. Fischer, P. Löper, K. W. Krämer, D. Biner, M. Hermle and S. W. Glunz, Sol. Energ. Mat. Sol. C., 2011, 95, 19601963

79 S. Fischer, J. C. Goldschmidt, P. Löper, G. H. Bauer, R. Brüggemann, K. Krämer, D. Biner, M. Hermle and S. W. Glunz, J. Appl. Phys., 2010, 108, 044912. 
80 S. Fischer, A. Ivaturi, B. Fröhlich, M. Rüdiger, A. Richter, K. W. Krämer, B. S. Richards and J. C. Goldschmidt, IEEE J. Photovolt., 2014, 4, 183 - 189.

81 S. K. MacDougall, A. Ivaturi, J. Marques-Hueso, K. W. Krämer and B. S. Richards, Sol. Ener. Mat. Solar Cells, 2014, 128, 18 - 26.

82 A. Ivaturi, S. K. MacDougall, R. Martín-Rodríguez, M. Quintanilla, J. Marques-Hueso, K. W. Krämer, A. Meijerink and B. S. Richards, J. Appl. Phys., 2013, 114, 013505.

83 J. Goldschmidt, S. Fischer, B. Herter, B. Fröhlich, K. Krämer, B. Richards, A. Ivaturi, S. MacDougall, J. M. Hueso, E. Favilla and M. Tonelli, Proceedings of the European Photovoltaic Solar Energy Conference and Exhibition (EU PVSEC), 2014, p. 1AP.1.2.

84 J. de Wild, J. K. Rath, A. Meijerink, W. G. J. H. M. van Sark and R. E. I. Schropp, Sol. Energ. Mat. Sol. C., 2010, 94, 2395-2398.

85 J. de Wild, A. Meijerink, J. K. Rath, W. G. J. H. M. van Sark and R. E. I. Schropp, Sol. Energ. Mat. Sol. C., 2010, 94, 1919-1922.

86 J. de Wild, T. Duindam, J. Rath, A. Meijerink, W. Van Sark and R. Schropp, IEEE J. Photovolt., 2013, 3, 17-21.

87 M. Liu, Y. Lu, Z. Xie and G. Chow, Sol. Energ. Mat. Sol. C., 2011, 95, $800-803$.

88 G.-B. Shan and G. P. Demopoulos, Adv. Mater, 2010, 22, 4373-4377.

89 L. Li, Y. Yang, R. Fan, Y. Jiang, L. Wei, Y. Shi, J. Yu, S. Chen, P. Wang, B. Yang and W. Cao, J. Power Sources, 2014, 264, $254-261$.

90 C. Yuan, G. Chen, P. N. Prasad, T. Y. Ohulchanskyy, Z. Ning, H. Tian, L. Sun and H. Agren, J. Mater. Chem., 2012, 22, 16709-16713.

91 J. Chang, Y. Ning, S. Wu, W. Niu and S. Zhang, Adv. Funct. Mater., 2013, 23, 5910-5915.

92 P. Ramasamy, P. Manivasakan and J. Kim, RSC Adv., 2014, 4, 3487334895.

93 T. F. Schulze, Y. Y. Cheng, B. Fückel, R. W. MacQueen, A. Danos, N. J. L. K. Davis, M. J. Y. Tayebjee, T. Khoury, R. G. C. R. Clady, N. J. EkinsDaukes, M. J. Crossley, B. Stannowski, K. Lips and T. W. Schmidt, Aust. J. Chem., 2012, 65, 480-485.

94 R. W. MacQueen, T. F. Schulze, T. Khoury, Y. Y. Cheng, B. Stannowski, K. Lips, M. J. Crossley and T. Schmidt, SPIE Solar Energy + Technology, 2013, pp. 882408-882408.

95 T. F. Schulze, J. Czolk, Y.-Y. Cheng, B. Fuckel, R. W. MacQueen, T. Khoury, M. J. Crossley, B. Stannowski, K. Lips, U. Lemmer et al., J. Phys. Chem. C, 2012, 116, 22794-22801.

96 A. Nattestad, Y. Y. Cheng, R. W. MacQueen, T. F. Schulze, F. W. Thompson, A. J. Mozer, B. Fckel, T. Khoury, M. J. Crossley, K. Lips, G. G. Wallace and T. W. Schmidt, J. Phys. Chem. Lett., 2013, 4, 2073-2078.

97 M. J. Y. Tayebjee, Ph.D. thesis, The University of Sydney, School of Chemistry, 2012.

98 N. J. Ekins-Daukes and T. W. Schmidt, Appl. Phys. Lett., 2008, 93, 063507.

99 C. M. Johnson and G. J. Conibeer, Journal of Applied Physics, 2012, 112, 103108.

100 A. C. Atre and J. A. Dionne, J. Appl. Phys., 2011, 110, 034505.

101 J. A. Briggs, A. C. Atre and J. A. Dionne, J. Appl. Phys., 2013, 113, 124509.

102 S. Baluschev, V. Yakutkin, G. Wegner, T. Miteva, G. Nelles, A. Yasuda, S. Chernov, S. Aleshchenkov and A. Cheprakov, Appl. Phys. Lett., 2007, 90, 181103.

103 S. Baluschev and T. Miteva, in Next Generation of Photovoltaics: New Concepts, Springer, 2012, pp. 157-190.

104 T. F. Schulze, Y. Y. Cheng, T. Khoury, M. J. Crossley, B. Stannowski, K. Lips and T. W. Schmidt, Journal of Photonics for Energy, 2013, 3, 034598-034598.

105 D. Sweet, E. Ott and J. A. Yorke, Nature, 1999, 399, 315-316.

106 M. Rüdiger, S. Fischer, J. Frank, A. Ivaturi, B. S. Richards, K. W. Krämer, M. Hermle and J. C. Goldschmidt, Solar Energy Materials and Solar Cells, 2014, 128, 57-68.
107 J. C. Goldschmidt, P. Loper, S. Fischer, S. Janz, M. Peters, S. Glunz, G. Willeke, E. Lifshitz, K. Kramer and D. Biner, Conference on Optoelectronic and Microelectronic Materials and Devices (COMMAD), 2008, pp. 307-311.

108 A. Monguzzi, D. Braga, M. Gandini, V. C. Holmberg, D. K. Kim, A. Sahu, D. J. Norris and F. Meinardi, Nano Letters.

109 R. W. MacQueen, Ph.D. thesis, The University of Sydney, School of Chemistry, 2014.

110 R. W. MacQueen, Y. Y. Cheng, A. N. Danos, K. Lips and T. W. Schmidt, RSC Adv., 2014, 4, 52749-52756.

111 Y. Y. Cheng, A. Nattestad, T. F. Schulze, R. W. MacQueen, B. Fückel, K. Lips, G. G. Wallace and T. W. Schmidt, 2014, in preparation.

112 J. You, L. Dou, K. Yoshimura, T. Kato, K. Ohya, T. Moriarty, K. Emery, C.-C. Chen, J. Gao, G. Li et al., Nat. Commun., 2013, 4, 1446.

113 S. Günes, H. Neugebauer and N. S. Sariciftci, Chem. Rev., 2007, 107, 1324-1338.

114 M. Grätzel, Accounts Chem. Res., 2009, 42, 1788-1798.

115 A. Yella, C.-L. Mai, S. M. Zakeeruddin, S.-N. Chang, C.-H. Hsieh, C.-Y. Yeh and M. Grätzel, Angew. Chem., 2014, 126, 3017-3021.

116 A. Yella, H.-W. Lee, H. N. Tsao, C. Yi, A. K. Chandiran, M. K Nazeeruddin, E. W.-G. Diau, C.-Y. Yeh, S. M. Zakeeruddin and M. Grätzel, Science, 2011, 334, 629-634.

117 T. Ameri, G. Dennler, C. Waldauf, H. Azimi, A. Seemann, K. Forberich, J. Hauch, M. Scharber, K. Hingerl and C. J. Brabec, Adv. Funct. Mater., 2010, 20, 1592-1598.

118 A. Colsmann, M. Reinhard, T.-H. Kwon, C. Kayser, F. Nickel, J. Czolk, U. Lemmer, N. Clark, J. Jasieniak, A. Holmes and D. Jones, Sol. Energy Mat. Sol. Cells, 2012, 98, 118-123.

119 Z. He, C. Zhong, S. Su, M. Xu, H. Wu and Y. Cao, Nat. Photonics, 2012, 6, 591-595.

120 H. Hoppe, N. Arnold, N. Sariciftci and D. Meissner, Sol. Energ. Mat. Sol. C., 2003, 80, $105-113$.

121 M. Grätzel, J. Photoch. Photobio. C, 2003, 4, 145-153.

122 A. Hagfeldt, G. Boschloo, L. Sun, L. Kloo and H. Pettersson, Chem. Rev., 2010, 110, 6595-6663.

123 Y. Murakami, Chem. Phys. Letters, 2011, 516, 56-61.

124 M. A. Green, K. Emery, Y. Hishikawa, W. Warta and E. D. Dunlop, Prog. Photovolt: Res. Appl., 2014, 22, 701-710.

125 M. Rohde, M. Zelt, O. Gabriel, S. Neubert, S. Kirner, D. Severin, T. Stolley, B. Rau, B. Stannowski and R. Schlatmann, Thin Solid Films, 2014, 558, 337-343.

126 O. Khaselev and J. A. Turner, Science, 1998, 280, 425-427.

127 S. Y. Reece, J. A. Hamel, K. Sung, T. D. Jarvi, A. J. Esswein, J. J. Pijpers and D. G. Nocera, Science, 2011, 334, 645-648.

128 F. F. Abdi, L. Han, A. H. Smets, M. Zeman, B. Dam and R. van de Krol, Nat. Commun., 2013, 4, 2195.

129 J.-H. Kim and J.-H. Kim, J. Am. Chem. Soc., 2012, 134, 17478-17481.

130 R. R. Islangulov and F. N. Castellano, Angew. Chem. Int. Ed., 2006, 45, 5957-5959.

131 Z. Jiang, M. Xu, F. Li and Y. Yu, J. Am. Chem. Soc., 2013, 135, 1644616453.

132 V. Gray, D. Dzebo, M. Abrahamsson, B. Albinsson and K. MothPoulsen, Physical Chemistry Chemical Physics, 2014, 16, 1034510352.

133 A. N. Danos, R. W. MacQueen, Y. Y. Cheng, M. J. Y. Tayebjee, M. Dvorak, T. Darwish and T. W. Schmidt, 2014, in preparation.

134 C. M. Johnson, P. J. Reece and G. J. Conibeer, Optics letters, 2011, 36, 3990-3992.

135 C. Hofmann, B. Herter, J. Gutmann, J. Löffler, S. Fischer, S. Wolf, R. Piper, N. Ekins-Daukes, N. Treat and J. C. Goldschmidt, Proc. SPIE, 91400H-91400H-9, 2014.

136 S. Schietinger, T. Aichele, H.-Q. Wang, T. Nann and O. Benson, Nano 
Lett., 2009, 10, 134-138.

137 S. Baluschev, F. Yu, T. Miteva, S. Ahl, A. Yasuda, G. Nelles, W. Knoll and G. Wegner, Nano Lett., 2005, 5, 2482-2484.

138 K. Poorkazem, A. V. Hesketh and T. L. Kelly, J. Phys. Chem. C, 2014, 118, 6398-6404.

139 A. C. Atre, A. García-Etxarri, H. Alaeian and J. A. Dionne, J. Opt., 2012, 14, 024008.

140 P. C. Boutin, K. P. Ghiggino, T. L. Kelly and R. P. Steer, J. Phys. Chem. Lett., 2013, 4, 4113-4118.

141 J. Peng, X. Jiang, X. Guo, D. Zhao and Y. Ma, Chem. Commun., 2014, 50, 7828-7830.

142 S. Baluschev, J. Jacob, Y. S. Avlasevich, P. E. Keivanidis, T. Miteva, A. Yasuda, G. Nelles, A. C. Grimsdale, K. Müllen and G. Wegner, ChemPhysChem, 2005, 6, 1250-1253.

143 P. Duan, N. Yanai and N. Kimizuka, J. Am. Chem. Soc., 2013, 135, 19056-19059.

144 J. S. Lissau, D. Nauroozi, M.-P. Santoni, S. Ott, J. M. Gardner and A. Morandeira, J. Phys. Chem. C, 2013, 117, 14493-14501.

145 A. Turshatov, D. Busko, Y. Avlasevich, T. Miteva, K. Landfester and S. Baluschev, ChemPhysChem, 2012, 13, 3112-3115.

146 J.-H. Kim, F. Deng, F. N. Castellano and J.-H. Kim, ACS Photonics, 2014, 1, 382-388.

147 Q. Liu, B. Yin, T. Yang, Y. Yang, Z. Shen, P. Yao and F. Li, J. Am. Chem. Soc., 2013, 135, 5029-5037.

148 C. Wohnhaas, A. Turshatov, V. Mailander, S. Lorenz, S. Baluschev, T. Miteva and K. Landfester, Macromol. Biosci., 2011, 11, 772-778.

149 J.-H. Kang and E. Reichmanis, Angew. Chem., 2012, 124, 12011-12014.

150 C. Wohnhaas, K. Friedemann, D. Busko, K. Landfester, S. Baluschev, D. Crespy and A. Turshatov, ACS Macro Letters, 2013, 2, 446-450.

151 A. Turshatov, D. Busko, S. Baluschev, T. Miteva and K. Landfester, New J. Phys., 2011, 13, 083035.

152 M. Filatov, I. Ilieva, K. Landfester and S. Baluschev, in Nanotechnology 2013: Bio Sensors, Instruments, Medical, Environment and Energy (Volume 3), Nano Science and Technology Institute (NSTI), 2013, ch. 6: Solar Power Technologies \& Materials, Title: Exploring the IRlimit of the Triplet-Triplet Annihilation Upconversion: Tetraaryltetraanthra[2,3]porphyrin - family, pp. 531-534.

153 F. Marsico, A. Turshatov, R. Peköz, Y. Avlasevich, M. Wagner, K. Weber, D. Donadio, K. Landfester, S. Baluschev and F. R. Wurm, J. Am. Chem. Soc., 2014, just accepted, DOI: 10.1021/ja5049412.

154 T. N. Singh-Rachford and F. N. Castellano, J. Phys. Chem. A, 2008, 112, $3550-3556$.

155 N. K. Giri, C. P. Ponce, R. P. Steer and M. F. Paige, Chem. Phys. Letters, 2014, 598, 17-22.

156 S. K. Sugunan, U. Tripathy, S. M. K. Brunet, M. F. Paige and R. P. Steer, J. Phys. Chem. A, 2009, 113, 8548-8556. 